\title{
The Phonology of Boundaries and Secondary Stress in Russian Compounds*
}

\author{
Maria Gouskova
}

\section{Introduction}

Although syntactically, canonical compounds are single words, phonologically, they often act as if they are somewhere between words and phrases. The phonological diagnostics that identify words and word edges often misfire when applied to compounds. For example, in Turkish, vowel harmony applies within syntactic words but does not apply between compound stems (Kabak \& Vogel 2001). In English and Icelandic, compounds have a special stress pattern, which differs systematically from the stress pattern of single-root words and from that of phrases (see Orešnik 1971 on Icelandic; Liberman \& Prince 1977 et seq. on English). In Russian, compounds are allowed to have secondary stress even though a single-root word can only have a single stress (Gouskova \& Roon 2008). One popular approach explains the special phonology of compounds by assigning them a special prosodic structure: they are parsed into recursive prosodic words or a clitic group, even though this option is marked or unavailable for non-compound words (McCarthy \& Prince 1993b; Booij 1995; Selkirk 1995; Peperkamp 1997; Ito \& Mester 2006; Kabak \& Revithiadou 2008; Ito \& Mester 2009). The goal of this article is to show that special phonological exemptions for compounds do not necessarily follow from special prosodic structure. Drawing on several kinds of phonological evidence from Russian, I show that there is no phonological word boundary inside Russian compounds, so the explanation for their special stress properties resides elsewhere.

I argue that Russian compounds are single phonological words. Compounds have a special stress pattern, which some might take to be evidence of multiple prosodic words. When we look outside of stress, however, we see that other phonological rules of Russian do not treat the stem boundary in compounds as a prosodic word boundary. Instead, secondary stress surfaces in compounds due to a morpho-phonological constraint that requires morphological stems to project prominences. In order to admit constraints of this sort, the grammar must allow for a more direct interface between morphology and phonology than is allowed in an indirect access model (for discussion, see Nespor

${ }^{*}$ I would like to thank Tuuli Adams, Christina Bethin, Antonio Fábregas, Alec Marantz, Tore Nesset, Anthi Revithiadou, Kevin Roon, Jason Shaw, and the audience at the Center for Advanced Study of Theoretical Linguistics in Troms $\varnothing$, Norway for helpful feedback on this and related work. Thanks also to Erika Harris for assistance in acoustic data analysis. Special thanks are due to Harry van der Hulst, Jaye Padgett, and an anonymous reviewer for The Linguistic Review for their comments, which resulted in numerous improvements to this article. 
\& Vogel 1986; Selkirk 1995; Revithiadou 1999; Ito \& Mester 2006). This constraint is connected to positional markedness theory (Smith 2002), whereby constraints tie prominence-enhancing features such as stress to prominent positions.

One of the key contributions of the article is empirical. Russian compounds have not received much attention in generative phonology, even though, as I show, they shed light on the inner workings of lexical stress assignment, the prosodic contexts for voicing neutralization, and the phonology of lexically idiosyncratic vowel deletion in Russian. Taken individually, these processes appear to point to contradictory conclusions about the prosodic status of clitics and subordinating compounds, but I show that a unified analysis is possible. Moreover, I show that compounds offer some clues to a long-standing mystery in Russian phonology, namely, the location of default stress. Compound stems with fixed stress are stressed differently from stems with mobile stress. I suggest an explanation for this: in Russian, there are effectively two stress defaults, prosodic-word-initial and prosodic-word-final, and each holds of a relatively small subset of morphemes. The mobile stress stems are subject to a default phonology, whereas the fixed stress stems are not. This analysis, formalized using lexically indexed constraints (Pater 2006; Flack 2007; Becker 2008) in Optimality Theory (Prince \& Smolensky 2004), and it reconciles the two opposing views on Russian stress.

The article is organized as follows. I start by describing the morphological and phonological properties of subordinating compounds in Russian in Section 2. Section 2.1 deals with the morphological structure, and Section2.2 presents the patterns and analysis of secondary stress distribution in Russian compounds. I analyze the presence and the location of secondary stress in Sections 2.2.2 and 2.2.3 respectively. A couple of alternatives are considered next: a cyclic analysis in Section2.3, and a recursive prosodic word account in Section 2.4. Section 3 focuses on boundary-sensitive rules, which show that there are no prosodic word boundaries inside Russian subordinating compounds. In Sections 3.1-3.2, I present and analyze the patterns of voicing neutralization in Russian, with special attention to the role of prosodic word edges. In Section 3.3, I turn to vowel reduction, which is also sensitive to prosodic word edges. In Section 3.4, I report on the results of an acoustic study of vowel reduction. I then turn to the phonology of the linker vowel, which has some curious accentual properties that could be due to a stress-epenthesis interaction. In Section 4, I discuss evidence against this epenthetic account. Section 5 is the conclusion.

\section{Subordinating compounds in Russian: morphology and stress}

This article is concerned with subordinating (or thematic) compounds, a ubiquitous and productive type in Russian. ${ }^{1}$ These are formed by combining two or more stems with a linking vowel, underlined in (1). This linking vowel is similar to the linker found in Greek (Nespor \& Ralli 1996) and is

\footnotetext{
${ }^{1}$ Russian actually has at least three types of compounds, based on their phonological and morphological properties: coordinating, truncated, and subordinating compounds (Townsend 1975:201-207; Molinsky 1973; and Gouskova \& Roon 2008). Coordinating compounds raise few mysteries: they consist of words that are phonologically and syntactically independent by all diagnostics. The nature of truncated compounds is less clear. I discuss them briefly in Section 3.2, but otherwise truncated compounds are not addressed here since they raise enough issues to deserve detailed examination in future work.
} 
represented orthographically as either $-e-$ or $-o-$. Since the vowel is typically unstressed, it is realized as one of several unstressed allophones, including $[ə, \Lambda, i, \dot{i}]$ (reduction is discussed in more detail in Section 3.3). Throughout the article, I give more phonetic detail than is customary in discussions of Russian phonology, transcribing vowel reduction, devoicing/voicing assimilation, and stress. All of these details become relevant to subsequent discussion. The transcriptions reflect the pronunciations in standard Moscow Russian.

\section{(1) Subordinating compounds}
a. $\mathrm{l}^{\mathrm{j}}$ is $\underline{\Lambda} \mathrm{Svál}$
'lumber cutting'
cf. $\mathrm{l}^{\mathrm{j} e s}$ 'wood,' s-vs $\mathrm{l}^{\mathrm{j}}-\mathrm{it}^{\mathrm{j}}$ 'to fell, saw down'
b. gələvํlómkə
'puzzle'
cf. gəlıv-á 'head,' lım-átj 'to break, wrack'
c. əbırònə̄sp $\Lambda$ sóbnəst ${ }^{j}$ 'defense capability'

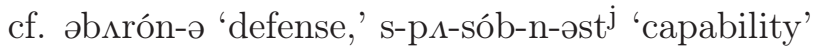

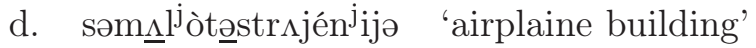
cf. sam- 'self,' ljit-átj 'to fly,' strıj-én j-ij-ə 'building'
e. jist $^{\mathrm{j}}{ }_{\text {ist }} \underline{\underline{\Lambda}} \mathrm{v}^{\mathrm{j}} \mathrm{e}^{\mathrm{j}} \mathrm{in}^{\mathrm{j}} \mathrm{ij}$ $\quad$ 'natural science'
cf. jist ${ }^{\mathrm{j}}$-istv-ó, 'nature,' $\mathrm{v}^{\mathrm{j}}$ éd- 'know'
f. jist ${ }^{j}$ istv $\underline{\underline{v}} \mathrm{v}^{\mathrm{j} e ́ t}$
'natural scientist'

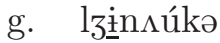
'pseudoscience'

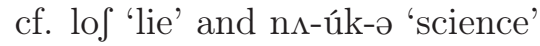

\subsection{Morphological structure of subordinating compounds}

The morphological head of a subordinating compound is the rightmost stem, which also bears the inflection for the whole compound. For now, "stem" will refer to the morphemes up to and including the linker vowel (e.g., gələv- $\Lambda^{-}$'head-linker'), or to the string of morphemes after the linker vowel (e.g., -lóm-k-ə 'break-nominalizer-nom. sg.'). A more precise structural definition of stems will be given at the end of this section. In terms of morphological composition, the left-hand stem is usually built from a bare root, though it may contain some derivational prefixes and suffixes (as in 1e). The right-hand stem may look like a free-standing word (e.g., [spısóbnəst ${ }^{j}$ ] 'capability' in 1c), but it may also look like a bare root (cf. 1e and 1f). If additional suffixes appear on the right-hand stem, they take scope over both stems as opposed to just the right-hand stem. Even if the string after the linker vowel looks like a free-standing word, the string does not necessarily bear any relation to that word. For example, the string $\left[-\mathrm{v}^{\mathrm{j}} \mathrm{e}^{\mathrm{j}}{ }^{\mathrm{i}}{ }^{\mathrm{j}} \mathrm{ij}\right.$ j] (roughly translatable as '-logy') often appears in compounds, but it bears little relation to the free-standing word $\left[\mathrm{v}^{\mathrm{j}} \mathrm{e}^{\mathrm{j}}{ }_{\mathrm{in}}^{\mathrm{j}} \mathrm{j}\right.$ j] 'jurisdiction.' Similarly, even though [lómkə] exists as a free-standing word meaning something like 'drug withdrawal symptoms,' it is not part of the structure or meaning of [gələv- $\underline{\underline{\Lambda}}-\mathrm{lóm}-\mathrm{k}-ə]$ ' 'puzzle' (literally, 'head breaker'). Rather, the nominalizer $-\mathrm{k}$ is attached to the compound stem. My analysis of the morpho-syntactic structure of this compound is shown in (2): 
(2) Structure for /golov-o-lom-k-a/ [gələv-뜨-lóm-k-ə] 'puzzle'

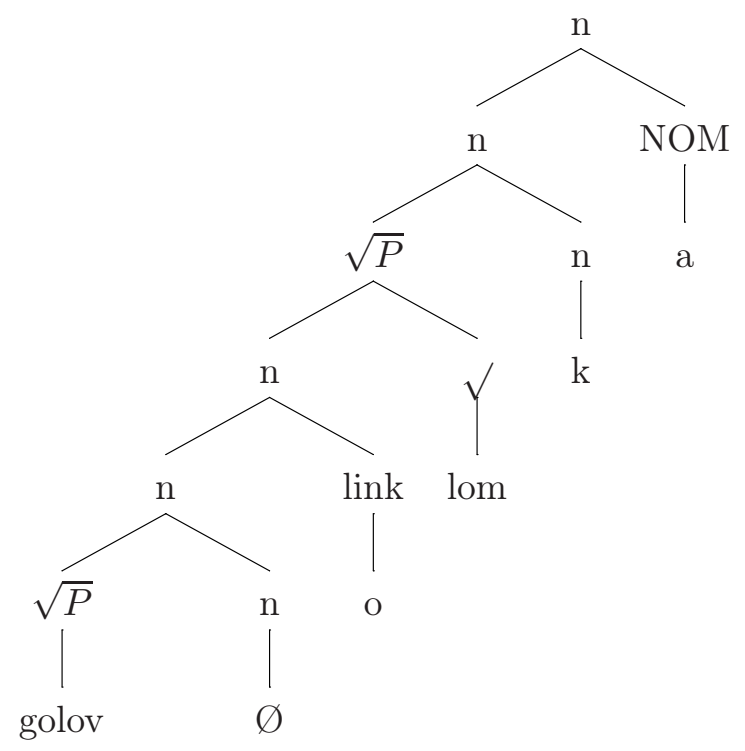

In the tree above, the linking vowel is given morphemic status and is a sister to the projection of the root golov- as opposed to lom-. I justify the lexical status of the linker in Section 4, which also explains what determines which linker is chosen for which stem. The syntactic relationship between golov- and lom- is that of argument and head, so I assume that the head lom- is higher in the structure so that it can govern the argument (cf. Harley 2008 on English). Though a large number of compounds are built on a head root and some complements, there are plenty of compounds that involve modifiers, for example, [liłnıúkə] 'pseudoscience.' In these compounds, the derivation starts out differently than for complement compounds, but the resulting structure is quite similar. 


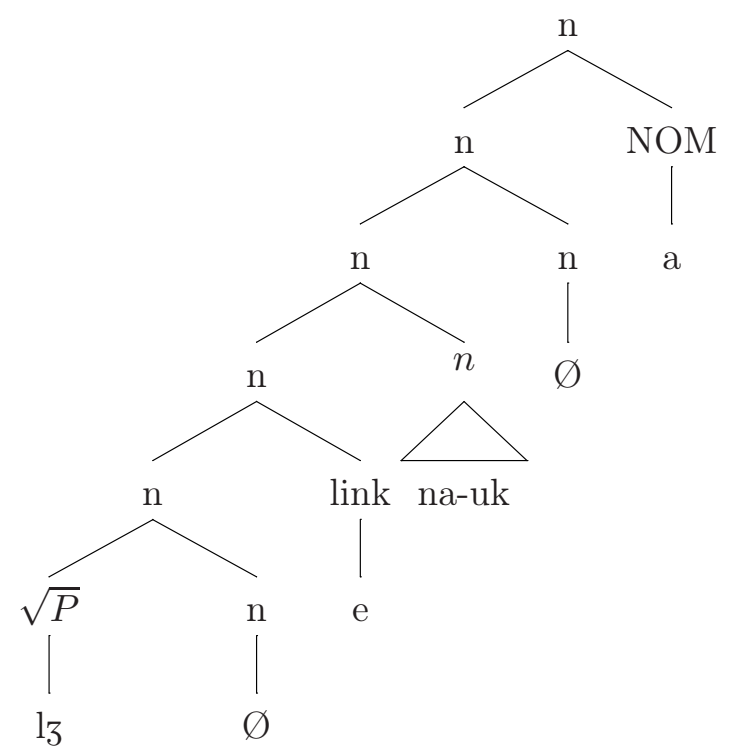

In the analysis of stress in the following section, I will need to make reference to some morphological constituents referenced by the phonology. For the purposes of defining what constitutes a "stem," I will assume that it is the projection immediately above the nominalizing or other categoryassigning suffix: in the case of subordinate stems, the projection of the linker, and for the head of the compound, the case suffix. Both the right-hand and the left-hand stems can be defined in a consistent way under this analysis. There may be a morphosyntactic generalization uniting both of these contexts, perhaps in terms of phases, though ultimately, the arguments for this need to come from outside of phonology. A morphological "word" is closed off by an inflectional projection-for nominal compounds, this is case.

\subsection{Phonology of stress in compounds}

\subsubsection{Descriptive generalizations}

The most remarkable property of compounds in the context of Russian phonology is stress. Unlike single-root words, compounds can have more than one stress under some circumstances (Yoo 1992; Kuznetsova 2006; Gouskova \& Roon 2008). The rightmost stem always bears a primary stress (Roon 2006), and it is always stronger than the stresses to its left. As for secondary stress, it is conditioned by a number of factors. For one thing, it is more likely to be present in compounds that are relatively rare, formal, or unfamiliar. Setting frequency and register aside, the pattern is as follows: ${ }^{2}$

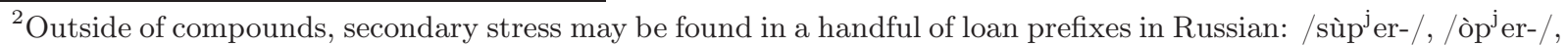
$/ \mathrm{ps}^{\mathrm{j}}$ èvdo-/. They could be lexical exceptions to the "one-stress-per-word" generalization; underlyingly stressed affixes whose stresses cannot be deleted even though the cost of keeping them is a Culminativity violation. One objection to this analysis is that it does not explain why suffixes can never be similarly exceptional. There is an alternative: Peperkamp (1997) treats similar Italian prefixes as roots or stems in their own right. The problem with this route
} 
(4) Secondary stress surfaces if both of the following conditions are met:

a. Stress is underlyingly present on the left-hand stem,

b. The secondary stress is separated by at least two syllables from the primary stress.

The generalization in (4) is exemplified below in (6), but first, we need a little background on Russian stress. Stress assignment in single-root words of Russian is complex and well-studied (Halle 1973, 1996; Halle \& Vergnaud 1987a; Melvold 1990; Idsardi 1992; Alderete 1999b; Revithiadou 1999; Crosswhite et al. 2003). Nominal roots in Russian can be classified into as many as six or more types based on stress patterns in inflectional paradigms (Zaliznjak 1977), but most analyses distinguish four main types. The first type, known as Pattern $\mathrm{A}$ in the literature, includes most nouns in Russian. These nouns have fixed stress on one of the syllables of the root in all inflected forms. All analyses assume that in Pattern A roots, stress is underlyingly specified (Melvold 1990; Alderete 1999b, and others). The second type, known as Pattern B, includes roots whose stress is fixed on the inflection, or on the rightmost syllable of the root if the inflection is null. The rest have mobile stress, which alternates between stem-intial and desinence stress (Pattern C) or between stem-final and desinence stress (Pattern D).

(5) Stress patterns in inflectional paradigms of underived nouns

\begin{tabular}{|c|c|c|c|}
\hline $\begin{array}{l}\text { Pattern A, fixed on root } \\
\text { /oborón-/ 'defense' }\end{array}$ & $\begin{array}{l}\text { Pattern B, inflection/final } \\
\text { /korablij-/ 'ship' }\end{array}$ & $\begin{array}{l}\text { Pattern C, mobile } \\
\text { /golov-/ 'head' }\end{array}$ & $\begin{array}{l}\text { Pattern D, mobile } \\
/ \text { kolj }^{\mathrm{j}} \text { es- / 'wheel' }\end{array}$ \\
\hline әbırón-ə (nom. sg.) & knráblj (nom. sg.) & gəlıv-á (nom. sg.) & kəl $\mathrm{j}_{\text {is-ó (nom. sg.) }}$ \\
\hline әbırón-əj (gen. sg.) & kər $\Lambda b^{j}{ }^{j}-1 ́$ (nom. pl.) & góləv-i (nom. pl.) & ks ljós-ə (nom. pl.) \\
\hline əbırón (gen pl) & kər $\Lambda$ blj-éj (gen pl) & gیlóf (gen pl) & $\mathrm{k} \Lambda \mathrm{l}^{\mathrm{j}}$ ós (gen pl) \\
\hline
\end{tabular}

For the purposes of compound secondary stress, the most important distinction is between fixed stress (Pattern A) stems and the rest. If stress appears on the affix in at least some of the inflected forms, then it is far less likely to surface as a secondary stress in compounds (as in 6c, e). Even in Pattern A stems (see 6a, b, d), however, the lexical stress does not usually surface if it is only one or fewer syllables away from the primary stress: compare (6a) and (6b). This suggests a prohibition on clashes. One final complication is that some stems surface without a vowel in compounds, and these may appear with stress on the linker vowel (see 6f) even if the stresses are "too close." These compounds tend to be low-frequency, but even in low-frequency compounds, the linker is only stressed when it is the only vowel in the left-hand stem. (For readability, I show only the morphological boundaries on either side of the linker vowel in the compounds below.)

is that there is no evidence that these morphemes have root status. They can never head words of their own, unlike other roots in Russian, and to posit that they are stems based on stress is circular. I leave this problem open for future research. 
(6) Examples of secondary stress
a. $\quad \mathrm{v}^{\mathrm{j}} \mathrm{ir}-\Lambda$-lómstvə
'treachery'
v jér-ə 'faith (nom. sg.),' v vér-u (acc sg)

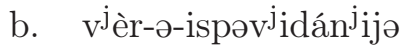
'denomination'

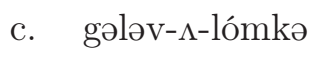
'puzzle'
gəlıv-á 'head,' góləv-ì (nom. pl.)
d. əbムròn-ə-spısóbnəst ${ }^{j}$
'defense capability'
əbırón-ə 'defense,' əbırón-əj (inst sg)

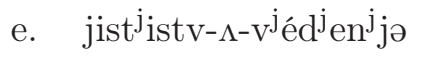
'natural science'
jist ${ }^{\mathrm{j}}$-istv-ó 'nature (nom. sg.), 'jist ${ }^{\mathrm{j}}$-éstf (gen pl)
f. $\mathrm{j}^{\mathrm{j}} \mathrm{n}-\mathrm{o}-\mathrm{z} \Lambda$ vót
'linen factory'
jón 'linen (nom. sg.), ' ljn-á (gen. sg.)

As mentioned earlier, the stress properties of subordinating compounds are surprising in the context of Russian phonology, since Russian normally allows only one stress per word regardless of length (see 7). Normally, then, stress could be considered a diagnostic for phonological wordhood. When applied to compounds, this stress diagnostic appears to identify two phonological words, though in only some of the compounds.

(7) Single-root words: only one stress per word (roots underlined)

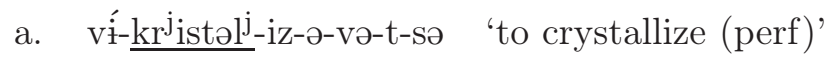

b. $\mathrm{kr}^{\mathrm{j}} \mathrm{istal}^{\mathrm{j}}$-iz- $\Lambda$-vá-t-sə 'to crystallize'

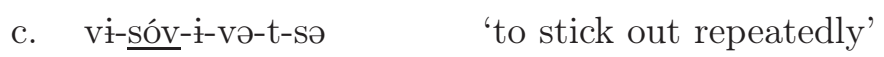

d. $\quad r \partial z-\underline{d r} \Lambda z^{-} t^{j}{ }^{j}-i^{j}-n-\partial s t t^{j} \quad$ irritability'

\subsubsection{Presence of secondary stress}

This section develops an analysis of secondary stress in compounds, which builds on Gouskova and Roon (2008). Here, I focus on the presence or absence of secondary stress, and the next discusses the location of secondary stress. The prosodic structure of Russian subordinating compounds is as shown in (8): compounds with only a primary stress have a single iambic foot and any number of unfooted syllables, whereas compounds with a primary and a secondary stress have two feet, one for each stress. (Throughout the article, I use "()" for foot boundaries, "." for syllable boundaries, "[l" for prosodic word edges, and " \{\} " for phonological phrase edges.)

(8) Prosodic structure of subordinating compounds
a. [gə.lə(vı.lóm)kə]

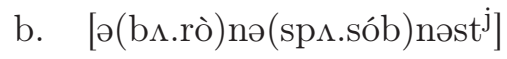
c. $\left[\left(\mathrm{l}^{\mathrm{j}} \mathrm{nò}\right)(\mathrm{z} \Lambda . v o ́ t)\right]$

The difference in stress between compounds and single-root words is due to a constraint called $\mathrm{STEM} \rightarrow \mathrm{PROM}$, which requires each morphological stem to contain at least one segment that projects a phonological prominence (cf. Fitzgerald's 2001 Morpheme-TO-STress Principle and Alderete's 1999b Post-Stem-Prom, also Revithiadou 1999), defined in (9). See Section 2.1 on what counts as a "stem" for the purposes of evaluating this constraint. I discuss this constraint further in Section 
(9) Morphology-phonology interface constraint

$\mathrm{STEM} \rightarrow \mathrm{PROM}(\mathrm{ST} \rightarrow \mathrm{PR}):$ "For each stem, assign a violation mark if no segment affiliated with the stem projects a prominence on the grid."

$\mathrm{STEM} \rightarrow$ PROM conflicts with markedness constraints on rhythm (see (10)). These include the constraint ${ }^{*} \mathrm{FTFT}$, which is often implicated in ternary stress patterns (see also Kager's 2001 "rarefy at peaks"). This constraint will produce the effect of penalizing both adjacent stresses and stresses separated by one unstressed syllable. ${ }^{*} \mathrm{FTFT}$ only applies PWd-internally in Russian - stresses may clash quite directly in phrasal phonology. Also important are constraints whose interaction results in the one-foot-per-word pattern, which include ENDRULE-L. ENDRULE-R is never violated in Russian, since the main stress is always the rightmost one even if it is not the only stress in the word.

(10) Prosodic markedness constraints

a. *FTFT: "Assign a violation mark for every pair of adjacent feet dominated by the same PWd." (after Kager 1994)

b. EndRule-L (ER-L): "A word-level prominence is not preceded by another prominence at the word level." (after Prince 1983; see also McCarthy 2003)

Secondary stress surfaces if it is underlying, but stresses are not normally inserted in the lefthand stem. This points to the activity of faithfulness constraints. Gouskova \& Roon (2008) adopt Alderete's (1999b) faithfulness constraints, defined informally as follows:

(11) Faithfulness to stress

$$
\begin{aligned}
& \text { MAx(stress) "No deletion of stress" } \\
& \text { DeP(stress) "No insertion of stress" } \\
& \text { NoFlop(stress) "No movement of stress" }
\end{aligned}
$$

Compounds are by default required to have two stresses - unlike non-compounds, which can only surface with one stress even if more than one morpheme is accented underlyingly $(12 \mathrm{a}, \mathrm{b})$. This is because ENDRULE-L dominates MAX(stress), requiring that the main stress be the only stress in non-compounds. STEM $\rightarrow$ Prom in turn dominates EndRule-L, and so two stresses surface in compounds $(12 \mathrm{c}, \mathrm{d}):^{3}$

\footnotetext{
${ }^{3}$ Throughout, I use comparative tableaux (Prince 2000). Each constraint that favors the winner over a loser has a "W" in its cell, and each constraint that favors a loser has an "L." In order for a ranking to obtain, each L has to be preceded by at least one $\mathrm{W}$ in a row of a tableau. The first few tableaux are presented in a hybrid format, combining traditional and comparative tableau notation.
} 


\begin{tabular}{|c|c|c|c|}
\hline$/$ ví-, $\mathrm{kr}^{\mathrm{j}}$ istál, -iz, -o, -va, - $\mathrm{t}^{\mathrm{j}},-\mathrm{s}^{\mathrm{j}} \mathrm{a} /$ & $\mathrm{ST} \rightarrow \mathrm{PR}$ & ER-L & MAX(stress) \\
\hline a. 嘫 [(ví) $\mathrm{kr}^{\mathrm{j}} \mathrm{i}$ i.stə.l li.zəvə.tsə] $^{\mathrm{j}}$ & & & * \\
\hline b. [vì) $\left(\mathrm{kr}^{\mathrm{j}}\right.$ istá) $\mathrm{l}^{\mathrm{j}} \mathrm{i}$.zə.və.tsə] & & $* ! \mathrm{W}$ & $\mathrm{L}$ \\
\hline \multicolumn{4}{|l|}{ / / vér-o-iz-po-v jed-án-ij-o/ } \\
\hline 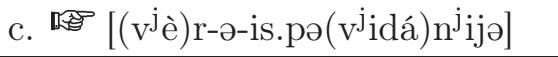 & & $*$ & \\
\hline 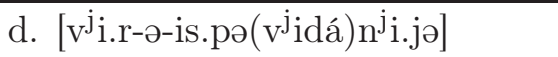 & $* ! \mathrm{W}$ & $\mathrm{L}$ & $* \mathrm{~W}$ \\
\hline
\end{tabular}

When the underlying position of the stress on the left-hand stem is too close to the main stress, $\mathrm{ST} \rightarrow \mathrm{PR}$ cannot be satisfied. This would violate the higher-ranked *FTFT. To resolve this conflict, the left-hand stem's stress is deleted. (For now, we are focusing on Pattern A stems, since their underlying stressedness is uncontroversial; other types of stems are examined at the end of this section and in Section 2.2.3).

(13) Compounds normally do not have stress clashes; underlying accent is deleted to avoid clash

\begin{tabular}{|l||c|c|c|c|}
\hline$/ \mathrm{v}^{\mathrm{j}}$ ér-o-lóm-stv-o & ${ }^{*} \mathrm{FTFT}$ & $\mathrm{ST} \rightarrow \mathrm{PR}$ & ER-L & MAX \\
\hline \hline a. ${ }^{\text {啗 }}\left[\mathrm{v}^{\mathrm{j}} \mathrm{i}(\mathrm{r}-\Lambda\right.$-lóm $)$ stvə] & & $*$ & & $*$ \\
\hline b. $\left[\left(\mathrm{v}^{\mathrm{j}} \mathrm{è}\right)(\mathrm{r}-\Lambda\right.$-lóm $)$ stvə] & $* ! \mathrm{W}$ & $\mathrm{L}$ & ${ }^{*} \mathrm{~W}$ & $\mathrm{~L}$ \\
\hline
\end{tabular}

An underlying stress could in principle surface somewhere other than its underlying location in longer stems. Under this option, /rabót-o-dát_ ${ }^{j} \mathrm{el}^{\mathrm{j}} /$ 'employer' would be *[ràbətı 'át $\left.^{\mathrm{j}} \mathrm{l}^{\mathrm{j}}\right]$ instead of the actually attested [rəbət $\Lambda$ dát $\left.{ }^{j} i^{j}{ }^{j}\right]$ (cf. rıbót-ə 'work (nom. sg.)'). This option is ruled out by an undominated NoFlop(stress). Faithfulness also explains why roots lacking a fixed stress cannot satisfy $\mathrm{ST} \rightarrow \mathrm{PR}$ by inserting stress. This suggests that $\mathrm{DEP}($ stress) dominates $\mathrm{ST} \rightarrow \mathrm{Pr}$. DeP must also dominate *LAPSE "no adjacent unstressed syllables," since stress is not typically inserted no matter how long the word is.

(14) Stress cannot be inserted to satisfy $\mathrm{ST} \rightarrow \mathrm{PR}$

\begin{tabular}{|c|c|c|c|}
\hline /golov-, -o-, kruz-, én-ij-o/ & DEP & $\mathrm{ST} \rightarrow \mathrm{PR}$ & ${ }^{*}$ LAPSE \\
\hline a. 噌 [gə.lə.v-ə.-(kru.zé)n $\left.n^{\mathrm{j}} \mathrm{i} . \mathrm{j} \partial\right]$ & & * & $* *$ \\
\hline 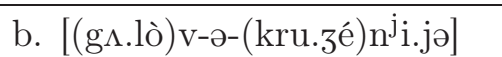 & $* ! \mathrm{W}$ & $\mathrm{L}$ & $\mathrm{L}$ \\
\hline
\end{tabular}

Regardless of whether there is secondary stress or not, the main stress always falls on the right-hand stem, i.e., the morphological head. This is the opposite of English, where main stress generally falls somewhere other than the morphological head (Selkirk 1984 and others). The relevant constraint is HeadStemStress, which is undominated in Russian. This constraint is a more specific version of $\mathrm{ST} \rightarrow \mathrm{PR}$, and it requires information about the head status of morphemes (similarly to the theory of Revithiadou 1999).

(15) HeadStemStress: "For each morphological head, assign a violation mark if no segment 
affiliated with the stem of the morphological head projects a word-level prominence on the grid."

If the head stem is as defined in Section 2.1, HeadStemStress will be satisfied as long as the word-level prominence is located somewhere to the right of the linker vowel. In this, my analysis departs from Roon's (2006) account, where the relevant constraint required Output-Output identity in stress placement between the morphological head and its free-standing base. This covers words like [ $\mathrm{k}^{\left.\mathrm{j} i n-ə-\mathrm{Zv}^{\mathrm{j}} \mathrm{izd}-\mathrm{a}\right]}$ 'film star', which have free-standing correspondent base words. The head stem of a compound does not always have such a base, however. It should also be noted that subordinating compounds are obligatorily headed, so HEADSTEMSTRESS is applicable generally.

Most of the phonological generalizations that hold in familiar compounds can be set aside in low-frequency/unfamiliar compounds. In these, secondary stress is found even if the left-hand stem is not of Pattern A. Low-frequency compounds are required to have stress because $\mathrm{ST} \rightarrow \mathrm{PR}$ is doubly instantiated in the hierarchy of Russian: the general version is ranked below DEP and the anti-clash constraint, whereas the version that applies to low-frequency words $\left(\mathrm{ST}_{\mathrm{T}} \rightarrow \mathrm{PR}_{\text {LowFreq }}\right)$ is undominated. ${ }^{4}$ This predicts that low-frequency stems containing vowelless roots should have stress, which is placed on the only available syllable: the one with the linker vowel as its nucleus. This placement of accent violates *FTFT; it also violates DEP(Accent).

(16) Even the linker vowel may be stressed in low-frequency compounds

\begin{tabular}{|c|c|c|}
\hline$/ \mathrm{l}^{\mathrm{j}} \mathrm{n}-$, o-, za-vód $/$ Low Freq & $\mathrm{ST} \rightarrow \mathrm{PR}_{\text {LowFreq }}$ & DEP $*{ }^{*} \mathrm{FTFT}$ \\
\hline a. 噌 $\left[\left(\mathrm{l}^{\mathrm{j}} \mathrm{n}-\mathrm{o}\right)-(\mathrm{z} \Lambda\right.$.vót $\left.)\right]$ & & $*$ \\
\hline b. $\left[1^{\mathrm{j}} \mathrm{n}-\partial-(\mathrm{z} \Lambda \cdot v o ́ t)\right]$ & $* ! \mathrm{W}$ & $\begin{array}{ll}\mathrm{L} \\
\mathrm{I}\end{array}$ \\
\hline
\end{tabular}

It should be noted that there aren't many high-frequency compounds that have vowelless roots in their left-hand stems. One example is [sn-ə- $v^{j}{ }_{i d}^{j}$ énijə] 'dream, vision' (cf. [son] 'dream (nom. sg.),' [sn-á] (gen. sg.)). The analysis predicts that they will not have secondary stress - as long as we assume that the linker vowel and the root itself are underlyingly stressless (see next section). Furthermore, in order for the analysis in (16) to work, the linker vowel must be part of the projection of the compound root $\left[\mathrm{l}^{\mathrm{j}} \mathrm{n}-\right]$, which is not a given. A similar linker vowel in Greek compounds has been claimed to be epenthetic, i.e., lacking a morphological affiliation (Ralli 2003). I justify my assumption that the Russian linker is indeed a lexical vowel in Section 4.

\subsubsection{Location of secondary stress}

In stems of Pattern A, the location of stress is determined by faithfulness, but where is stress inserted in compounds with Pattern B and C stems? Some key examples are given in (17). The data are

\footnotetext{
${ }^{4}$ Like Gouskova \& Roon (2008), I assume that the constraint may be indexed to something other than frequencyit could be register, or even something like degree of morphological compositionality. Disentangling morphological complexity effects from frequency is a complex and controversial issue, but the phonological grammar must provide two options for realizing compound stress regardless of what its presence is expressing.
} 
based on a grammaticality judgment study (Gouskova \& Roon 2010), where speakers were asked to rate compounds that were pronounced without secondary stress or with stress in various positions, including the linker. ${ }^{5}$ Speakers generally prefer Pattern B and Pattern C stems without secondary stress - if stress is present, the pronunciation is relatively degraded. In multi-syllabic left-hand stems, the worst location for secondary stress is reliably the linker. The linker can only be stressed in low-frequency compounds, and only when the left-hand root is vowelless. This generalization is simple and apparently exceptionless; stress cannot fall on the linker vowel even in compounds formed with Pattern B stems. Pattern B usually has fixed inflection stress (as in 17e). The starred forms in (17d) and (17e) below are quite unacceptable to native speakers. As for the last two words, speakers' intuitions are subtle; I return to discuss those once the analysis is in place.

(17) Secondary stress location in words of Pattern B and C

\begin{tabular}{|c|c|c|c|c|}
\hline & stressless pronunciation & stressed & gloss & stress type \\
\hline a. & $\mathrm{l}^{\mathrm{j}} \mathrm{n}-\partial-\mathrm{z} \Lambda$ vót & $\mathrm{l}^{\mathrm{j}} \mathrm{n}$-ò-z $\Lambda$ vót & 'linen factory' & (B) \\
\hline b. & zl-ə-upətrijibljén $n^{\mathrm{j}} \mathrm{ij}$ & zl-ò-upətr ${ }^{\mathrm{j}} \mathrm{ibl}^{\mathrm{j}}$ en $^{\mathrm{j}} \mathrm{ij}$ & 'abuse' (lit. 'ill use') & (B) \\
\hline c. & 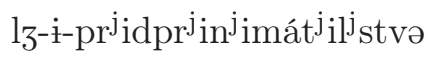 & $l_{3}$-è-pr ${ }^{\mathrm{j}}{ }_{i d p r}{ }^{j}{ }_{i n}{ }^{j}{ }_{i m a ́} t^{j}{ }^{j} 1^{j}$ stvə & 'fraudulent industry' & (B) \\
\hline d. & 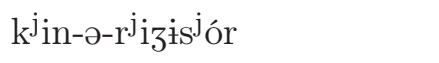 & 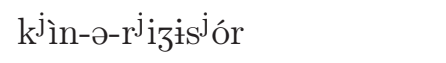 & 'film director' & (B) \\
\hline e. & skət-ə-prəmíf $\int \mathrm{l}^{\mathrm{j}}$ inəst $^{\mathrm{j}}$ & 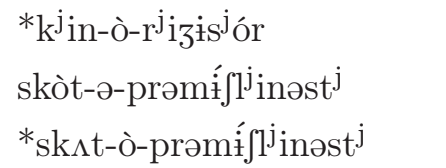 & 'cattle industry' & (B) \\
\hline f. & kərəblij-i-str $\Lambda$ jén ${ }^{j}$ ijə & 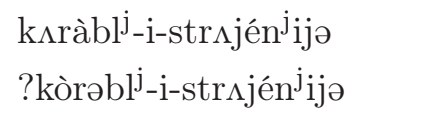 & 'ship building' & (B) \\
\hline g. & gələv- $\Lambda$ - $\mathrm{t}^{\mathrm{j}}$ ápstvə & 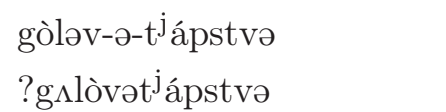 & 'negligence' & (C) \\
\hline
\end{tabular}

The biggest question raised by these data is why stress is so marked on the linker. The analysis in Section 2.2 certainly does not prevent stress from falling on the linker, and it even allows this placement in low-frequency compounds (see especially 16). The anti-clash constraint *FTFT will prefer for secondary stress to be at least two syllables away from the main stress, but in some of the longer compounds, the linker is far enough from the main stress to satisfy ${ }^{*} \mathrm{FTFT}$ : * $\left(\mathrm{k}^{\mathrm{j} i n-o ̀)}\right)$ $\mathrm{r}^{\mathrm{j}} \mathrm{i}\left(3_{\text {is }}^{\mathrm{j}} \mathrm{o}\right.$ r). Additional provisions are needed to explain the position of stress in such words, especially since the claim about Pattern $\mathrm{B}$ and $\mathrm{C}$ stems being unstressed is not an obvious one.

In order to understand the behavior of Pattern B and C stems, we need some background on how they are usually analyzed. All analyses treat Pattern A stems as lexically accented, but the analyses of Pattern B and C stress vary. Melvold (1990) treats Pattern B words as having a floating lexical accent. The accent flops to the suffix whenever one is available but docks on the last syllable of the root if there is no suffix. (Melvold's account is described in more detail in Section 2.3). Revithiadou

\footnotetext{
${ }^{5}$ Yoo (1992) is the only published source on compound stress that has extensive data; the problem is that the data come from several pronunciation dictionaries, where stress is transcribed inconsistently. Since stress is variable, dictionaries (especially prescriptive ones) are not the ideal source.
} 
(1999) develops a similar analysis but in OT. Halle (1973) and Alderete (1999b), on the other hand, assign stress to Pattern B words in the phonology; indeed, Alderete assumes that post-stem/final accent is the phonological default for Russian. For both Halle and Melvold, the default is initial for Pattern C stems; stress shows up on the first syllable whenever the root is combined with an unaccented suffix. A lexically accented suffix will get stress otherwise. Alderete's analysis stands alone in treating Pattern $\mathrm{C}$ stems as lexically indexed on the first syllable; their mobile stress arises from a grammatical pressure to distinguish morphologically related words from one another.

This debate about default stress in the language is an old one (see Crosswhite et al. 2003 for an overview). It is also a difficult question, since whatever the default is, it isn't the majority pattern: relatively few words follow patterns other than A. Compound accentuation offers a new piece of evidence, since in compounds, Pattern B and C stems pattern together. If we treat Pattern A roots as underlyingly accented, we can explain why they retain stress in compounds whenever clash can be avoided. Assuming that either Pattern B or Pattern C stems are underlyingly accented runs into a problem: Pattern B and $\mathrm{C}$ stems both lack secondary stress (on the linker or otherwise) even if clash is not an issue. The linker also strongly resists stress in Pattern B stems, which normally have post-root accent, and this is unexpected in some of the previous analyses of Russian stress.

This, then, is the explanation I will pursue here: Pattern B and C stems are both underlyingly unaccented, and so is the linker vowel. The difference between the two types of stems is that they follow different phonological defaults. For Pattern B, default stress is PWd-final, whereas the general default (demonstrated in inflectional paradigms of Pattern $\mathrm{C}$ and in other morphological contexts) is PWd-initial. I analyze this two-default system in terms of lexically indexed constraints (Pater 2000, 2006). Pattern B stems are indexed to the constraint in (18), which is violated whenever a PWd head (stressed syllable) is not rightmost in a Prosodic Word. The word-initial default for Pattern C stems, on the other hand, is imposed by a lower-ranking Align-L(PWd, Head), which demands that the head stressed syllable be PWd-initial.

(18) Align-R(PWd, Head $)_{B}$ : 'The right edge of a PWd coincides with the right edge of the Head of the PWd.' [Indexed to Pattern B roots]

(19) Align-L(PWd, Head): 'The left edge of a PWd coincides with the left edge of the Head of the PWd.'

Stress assignment in Pattern B and C words with inflectional affixes is analyzed in (21). Any PWd containing a pattern B root is evaluated by Align-R(PWd, Head) $)_{B}$. This constraint favors word-final stress both in affixed and in unaffixed forms; final stress is thus predicted in Pattern B forms regardless of whether the suffix is stressed or not. ${ }^{6}$ Align-R(PWd, Head) $B$ does not apply to Pattern C forms, so the account of these is similar to Melvold (1990). If none of the morphemes are accented, then stress is initial; if the suffix is stressed, then stress is on the suffix, because

\footnotetext{
${ }^{6}$ Pattern B and C forms with the nominal suffix /-ami/ 'inst. pl.' always have stress on the penult. This can be explained by a morpheme-specific ranking of NonFinality (Prince \& Smolensky 2004) above Align-R. Alderete (1999b) assumes that the default is not PWd-final but post-stem. My analysis could be thus modified to work for inflectional forms, but it would make the wrong predictions for compounds.
} 
faithfulness to stress outranks the phonological markedness constraints that enforce the default. There is no distinction in this account between Pattern A and Pattern C stems except that Pattern $\mathrm{C}$ stems are underlyingly unstressed; everything else follows from the ranking of faithfulness and markedness constraints. ${ }^{7}$

(20) Analysis of Pattern B and C stress in inflectional paradigms

\begin{tabular}{|c|c|c|c|c|}
\hline$/$ korablj $_{B}{ }^{\prime} /$ 'ship' & MAX(stress) & AligN-R $_{B}$ & ALIGN-L & AliGN-R \\
\hline kıráblj $\sim$ kórəbli $l^{j}$ & & $\mathrm{~W}$ & $\mathrm{~L}$ & W \\
\hline /korabli $-\mathrm{i} /(+$ nom. pl. $)$ & & & & \\
\hline 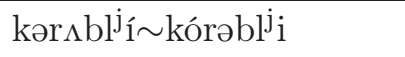 & & $\mathrm{W}$ & $\mathrm{L}$ & W \\
\hline /golov $C$-á/ 'head' & & & & \\
\hline gəlıvá〜góləvə & $\mathrm{W}$ & & $\mathrm{L}$ & $\mathrm{W}$ \\
\hline$/ \operatorname{golov}_{C}-\mathrm{i} /(+$ nom. pl. $)$ & & & & \\
\hline góləvĩ goləví & & & W & $\mathrm{L}$ \\
\hline
\end{tabular}

This analysis of stress in inflectional paradigms predicts that by default, compounds formed from Pattern B roots should surface without stress. In Section 2.2, I established the ranking of DEP(stress) over $\mathrm{ST} \rightarrow \mathrm{PR}$, which in turn dominates MAX(stress). Because Pattern B roots are unaccented, stress cannot be inserted on them to satisfy the compound prominence constraint, so they surface without secondary stress by default. This applies to Pattern $\mathrm{C}$ compounds, as well. Note that the presence of a Pattern B root in a compound does not necessarily impose PWd-final stress onto the head stem. An undominated constraint requires that stress fall on the morphological head of the compound (see 15). If one of the morphemes in the right-hand stem is stressed, then stress will fall on that morpheme, as required by faithfulness. Since MAX dominates Align-R and Align-L, stress will show up in its lexical location. This is shown in tableau (21). Otherwise, stress will be assigned much as in the inflectional paradigms for Pattern B and C stems.

(21) Analysis of stress in compounds

\begin{tabular}{|c|c|c|c|c|c|}
\hline 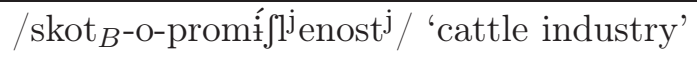 & DEP & $\mathrm{ST} \rightarrow \mathrm{PR}$ & MAX & Align-R $_{B}$ & Align-L \\
\hline \multicolumn{6}{|l|}{ 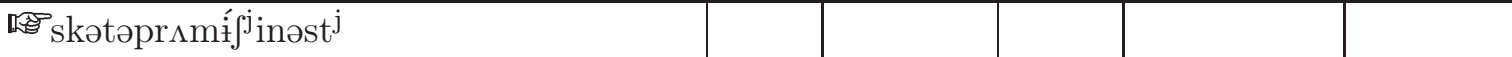 } \\
\hline skıtòpr $\Lambda$ míf $\int^{j}{ }^{j}{ }^{n} ə s t^{j}$ & W & $\mathrm{L}$ & & & \\
\hline skòtəprımíf $\int \mathrm{l}^{\mathrm{j}}$ inəst $^{\mathrm{j}}$ & W & $\mathrm{L}$ & & & \\
\hline skətəpr $\Lambda$ mi $\int l^{j}$ inóst $^{\mathrm{j}}$ & $\mathrm{W}$ & & $\mathrm{W}$ & $\mathrm{L}$ & \\
\hline
\end{tabular}

\footnotetext{
${ }^{7}$ Together with Revithiadou (1999) and Alderete (1999b), I assume that there is a positional constraint MAxRoot(stress), which outranks general MAx(stress) and decides in favor of leftmost (root) stress in cases where both the root and the suffix are stressed. This analysis predicts that if an accented stem were to be indexed as Pattern B, then it would be indistinguishable from a Pattern A stem, with initial stress winning every time. Unaccented Pattern B stems are the ones that show the final default.
} 
The analysis makes correct predictions for most low-frequency compounds, as well. If a compound with a subordinated Pattern B root is treated as a low frequency word, then it will surface with a stress. (I use the same word in the next tableau as in the previous tableau. Recall that the presence of secondary stress on low-frequency compounds is somewhat optional.) The stress is inserted, violating the high-ranking but dominated DEP(stress). In monosyllabic roots, stress will then fall on the first syllable.

(22) Analysis of stress in low frequency compounds

\begin{tabular}{|c|c|c|c|c|c|c|c|}
\hline$/ \operatorname{skot}_{B}{ }^{-O}-$ promíf $^{\prime} \mathrm{l}^{\mathrm{j}}$ enost $^{\mathrm{j}} L F /$ & $\mathrm{St} \rightarrow \operatorname{Pr}_{L F}$ & DEP & ${ }^{*} \mathrm{FTFT}_{\mathrm{T}}$ & $\mathrm{ST} \rightarrow \mathrm{PR}$ & MAX & $\mathrm{AL}-\mathrm{R}_{B}$ & AL-L \\
\hline (skò)tə(prsmíf $)^{j} \mathrm{l}_{\text {inest }}{ }^{j}$ & & & & & & & \\
\hline skətə(pr $(\operatorname{mí} \hat{f})]^{j}$ inəst $^{j}$ & $\mathrm{~W}$ & $\mathrm{~L}$ & & $\mathrm{~W}$ & & & \\
\hline$(\operatorname{sk} \Lambda$ tò $)\left(\operatorname{pr} \Lambda \mathrm{m} \dot{f} \int\right) \mathrm{l}^{\mathrm{j}}$ inəst $^{\mathrm{j}}$ & & & W & & & $\mathrm{L}$ & \\
\hline
\end{tabular}

In compounds where clash is not an issue (e.g., [ $\left[\mathrm{k}^{\mathrm{j}}\right.$ in-ə- $\mathrm{r}^{\mathrm{j}} \mathrm{i}^{\mathrm{i}} \mathrm{s}^{\mathrm{j}}$ or $]$ 'film director'), secondary stress is on the first syllable rather than on the linker. The word [ $\mathrm{k}^{\mathrm{j}}$ inó] 'film' is indeclinable and always surfaces with final stress, so it follows Pattern B for all intents and purposes. Nonetheless, in a compound, this stem cannot have stress on the second syllable, even if no clash results. The analysis actually predicts this to be the case: secondary stress should be initial in Pattern B and Pattern $\mathrm{C}$ stems alike. The reason for this is that the limited default imposed by Align-R(PWd, Head) $B$ cannot be satisfied by linker stress - the linker is not PWd-final. ALIGn-L, on the other hand, is general, not indexed, so initial stress is the next best option.

This prediction is for the most part borne out, especially in Pattern C stems, but there appears to be a subtle difference between the Pattern $\mathrm{C}$ compound [gələvstjápstvə] 'negligence' and the Pattern B compound [kərəb] ${ }^{j}$-i-str $\Lambda$ jén ${ }^{j}$ ijə] 'ship building.' I suggest the following explanation for this. The main distinction between Pattern $\mathrm{C}$ roots and Pattern $\mathrm{B}$ roots is that the former have initial stress in some of the inflectional forms, whereas longer Pattern B stems generally do not. Were it not for the orthography, Russian speakers would not even know the underlying quality of the vowel in stems like $\left[/ \operatorname{korabl}_{B}{ }_{B} /\right.$ 'ship.' This may play a role in the degraded grammaticality of compounds with multisyllabic Pattern B stems. Indeed, my own intuition is that 'ship building' would be better with initial stress than with second-syllable stress if the vowel in the first syllable is pronounced as [a] rather than [o]. Formalizing this intuition is far from straightforward, however, and it might have to be postponed until we have more facts about secondary stress assignment in Pattern B and C stems.

To summarize the results of this section, I demonstrated that treating Pattern B stems and Pattern $\mathrm{C}$ stems as unaccented and subject to different stress defaults allows us to explain where secondary stress falls in most cases. I sketched the basic analysis of primary stress in inflectional paradigms of Russian and showed that it combines straightforwardly with the analysis of secondary stress. It also makes the right predictions for the majority of cases, without additional stipulations. A few aspects of the analysis are worth highlighting. First, the default stress placement is defined 
by constraints familiar from work on fully regular stress systems, which assign stress to prosodic constituents rather than morphological ones. These constraints work for single-root words as well as compounds, provided we assume that compounds are single prosodic words. This assumption will be justified at length in Section 3. Second, treating both Pattern B and C stems as unaccented allows us to explain why they pattern together in lacking secondary stress. Other analyses do not necessarily get the facts right in compounds, especially for Pattern B stems. If Pattern B stems are accented (as in Melvold 1990; Revithiadou 1999), then why don't they surface with their accents in compounds, just like Pattern A stems do? If, on the other hand, they are unaccented but the default is post-stem (as in Alderete 1999b), then we expect secondary stress to show up on or even after the linker vowel. Linker stress is very marked, and post-linker secondary stress is completely unattested. Even though these analyses make some incorrect predictions, however, they bring important insights into how Russian stress works. My analysis attempts to reconcile the two long-standing views on default stress in Russian: the phonological default in the language as a whole is initial, but for some morphemes, it is final. This obviously makes a set of complicated predictions for the accentual behavior of derivational morphemes, which must be reserved for future exploration.

There are, of course, alternatives to this account. Melvold's cyclic analysis is discussed in the next section. Alderete's analysis could also work if we treat the linker vowel as epenthetic. The resistance of epenthetic vowels to accent is well-documented typologically, and there is no shortage of explanations for this in OT and in other frameworks (Broselow 2008; Alderete 1999a; see McCarthy 2007 for an overview). The idea that linkers are epenthetic also has some precedent in the work on Greek compounds, which are morphologically similar to Russian ones (Ralli 2003). There is, however, ample evidence that the linker is a lexical vowel present in the input (see Section 4).

In the following sections, I consider two kinds of alternatives to my account. First is a cyclic analysis, whereby stress is assigned to compound stems separately before they are phonologically concatenated (see Section 2.3). While this analysis brings some insight to the question of how primary stress is assigned in compounds, it cannot fully account for the descriptive generalizations about the placement and realization of secondary stress. The second alternative, discussed in Section 2.4 , is a recursive prosodic word account, whereby compounds either have secondary stress or not depending on whether they are parsed into recursive or non-recursive prosodic words. This analysis makes certain predictions about boundary-sensitive rules of Russian, which I take up in the rest of

the article. I argue that there is no evidence for prosodic word boundaries inside compounds, and along the way I provide a detailed account of their segmental phonology.

\subsection{A cyclic alternative}

\subsubsection{Introduction}

Cyclicity has a long and controversial history in generative work on Russian stress (Halle \& Vergnaud 1987a,b; Melvold 1990; Halle \& Kenstowicz 1991; see, especially, Melvold 1990; Alderete 1999b; Revithiadou 1999 for critiques). The intuition shared by all cyclic analyses is that stress is assigned to a morphological stem contained within a word before the rest of the word is phonologized. 
Stresses assigned on one cycle can be preserved in subsequent cycles, so morphologically complex words will be phonologically different from morphologically simple words. This suggests an analysis of compound stress. Under this analysis, each stem of a compound gets stress on its own cycle. Because compounds are phonologically special, each stem gets to keep its stress, and secondary stress is the result. As I will show, this account is not consistent with cyclic analyses of non-compound words of Russian. There is a more serious problem with these analyses: the cyclic/derivational account cannot capture the generalization about secondary stress in compounds: secondary stress is usually lexical stress. Ordered rules cannot capture this generalization because they do not retain a history of how an accent was assigned.

\subsubsection{Main features of the cyclic analysis}

Melvold (1990) develops a most thorough cyclic treatment of stress assignment Russian, so I will explore the predictions of her analysis for compounds. In Melvold's as well as in other accounts, any given morpheme in the Russian lexicon is specified as either accented or not. In multisyllabic accented morphemes, stress can fall on any syllable, but in the output, only one stress survives. This surface culminativity is guaranteed by the rule known as Basic Accentuation Principle, or BAP.

(23) Basic Accentuation Principle (Halle \& Vergnaud 1987a; Melvold 1990, and others)

Stress the leftmost accented vowel. If there isn't an accented vowel, stress the leftmost vowel in the stem.

The BAP has two more effects in addition to ensuring culminativity. First, it has the effect of stressing a root over a suffix, if both are accented. ${ }^{8}$ If the root is unaccented, the leftmost accented suffix gets stress. Second, if there are no accents in the word, the BAP acts as the default stress rule, assigning stress to the word-initial vowel. This explains why accent is "columnar" in Pattern A roots, and why the accent shifts between the initial syllable and inflectional suffixes in Pattern $\mathrm{C}$ roots. Pattern B roots are assumed to be subject to a special post-accenting rule: they have an underlying accent that migrates onto the suffix whenever one is available. (I do not discuss Pattern D here, which requires some extra mechanisms. See Melvold 1990.) This analysis, sketched out in (24), covers the phonology of morphologically simple roots with inflectional suffixes.

\footnotetext{
${ }^{8}$ In subsequent work on Russian, the prevalence of root accent over suffix accent has been ascribed to positional faithfulness (Alderete 1999b; Revithiadou 1999).
} 


\begin{tabular}{|l|l|l|l|}
\hline & $\begin{array}{l}\text { Pattern A (accented) } \\
\text { /paták-/ }\end{array}$ & $\begin{array}{l}\text { Pattern B (post-accenting) } \\
\text { /kanap-'/ }\end{array}$ & $\begin{array}{l}\text { Pattern C (unaccented) } \\
\text { /tapan-/ }\end{array}$ \\
\hline \hline Accented affix /-ú/ & $\begin{array}{l}\text { patáku } \\
\text { root accent survives }\end{array}$ & $\begin{array}{l}\text { kanapú } \\
\text { special accent shift rule }\end{array}$ & $\begin{array}{l}\text { tapanú } \\
\text { affix accent survives }\end{array}$ \\
\hline Unacc. affix /-la/ & $\begin{array}{l}\text { patákla } \\
\text { root accent survives }\end{array}$ & $\begin{array}{l}\text { kanaplá } \\
\text { special accent shift rule }\end{array}$ & $\begin{array}{l}\text { tápanla } \\
\text { default initial stress }\end{array}$ \\
\hline
\end{tabular}

The BAP is subject to the Strict Cycle Condition: it applies only to derived contexts (Mascaró 1976 et seq.). This assumption is necessary for two reasons. First, if the BAP got to apply to a Pattern $\mathrm{C}$ root before the affix cycle, then this pattern would be indistinguishable from Pattern A with fixed initial syllable stress. In order to account for mobile stress that alternates between the initial syllable and the affix, the BAP must be held off until two morphemes are put together. Second, there are suffixes (e.g., the nominalizer $/$-ost $^{\mathrm{j}} /$ ) that apparently trigger the initial default on unaccented roots without inducing Pattern $\mathrm{C}$ alternations. Melvold accounts for the absence of Pattern $\mathrm{C}$ in words with these suffixes by assuming that the derivational suffix is itself unaccented but that the affixation triggers the BAP. Therefore, even an accented inflectional suffix attaching to such a base of two unaccented morphemes will not erase a BAP-assigned stress.

Melvold's main contribution to thinking about lexical accent systems is introducing the notion of dominance as distinct from cyclicity. ${ }^{9}$ Dominance refers to the ability of an affix to impose its own stress pattern onto the base. Cyclicity plays a role in the analysis of "regular" (i.e., recessive) derivational suffixes: the unaccented ones can impose an initial default, but only on Pattern $\mathrm{C}$ roots. Dominant suffixes, on the other hand, impose a fixed stress pattern on any stem they attach to, by erasing the metrical structure imposed on previous cycles. Accented dominant suffixes surface with suffix stress, and unaccented ones surface with initial stress. Any suffix can therefore be arbitrarily specified as [ \pm dominant]; dominance simply determines whether the lexical accent of the base survives or not. Likewise, accentedness determines where stress falls. Coupled with cyclicity, the accented/dominant cross-categorization produces the richness of patterns found in derived nouns.

It should be noted that Melvold's is not the only account that assumes cyclicity. For a number of languages, it is enough to assume that what Melvold calls dominance really is cyclicity: dominant suffixes are cyclic, whereas recessive ones are not (Halle \& Mohanan 1985; Halle \& Vergnaud 1987b; Halle \& Kenstowicz 1991). This kind of analysis requires treating suffixes such as $/$ ost $^{\mathrm{j}} /$ and $/$ $\mathrm{en}^{\mathrm{j}} /$ as unanalyzed exceptions, however. Melvold's arguments have been largely adopted in much subsequent work (Inkelas 1996; Alderete 1999b; Revithiadou 1999).

\footnotetext{
${ }^{9} \mathrm{My}$ understanding of lexical accent systems significantly improved after discussions with Anthi Revithiadou.
} 


\subsubsection{Extension of cyclic anlaysis to compounds}

Melvold expressly excludes compounds from consideration in her thesis, and it is easy to see that the BAP analysis does not work for compounds without modifications. The reason is that BAP is a culminativity rule: it produces exactly one stress per word, whereas compounds can have two. Moreover, even if BAP were relaxed to allow for secondary stresses in compounds, it seems to make the wrong prediction for where the primary stress will be. Under the BAP, in a compound with two accented roots, primary stress should be on the first stem, not the second. This is wrong, as we have seen. Stress may or may not be present on the left-hand stem, but on the right-hand stem, stress is obligatory. This analysis would need a special compound rule that will allow for stress to be assigned to the morphological head of the compound, not to the leftmost accented vowel or the initial vowel. ${ }^{10}$

Provided that the cyclic BAP analysis can be modified to accommodate compounds, then the cyclic story would run as sketched in (25). To save space, I suppress the cycles involved in concatenating the suffixes in the right-hand stems, and I show how the cyclic derivations work for the separate stems side-by-side rather than serially. On cycle 2, stress is assigned in the left-hand and the right-hand stems. Once the left-hand and the right-hand stems of the compound are concatenated, one of the stresses is optionally removed. The destressing rule has to be triggered by the presence of a clash; it must also be blocked in case the compound is of low frequency.

(25) Cyclic account of compound stress in [gələv^lómkə] and [bjitónəmijálkə]

\begin{tabular}{|c|c|c|c|c|}
\hline $\mathrm{UR}$ & \multicolumn{2}{|c|}{ /golov-o-lom-ok-a/ } & \multicolumn{2}{|c|}{$/ b^{j}$ etón-o-m ${ }^{j} e \int-a ́-l-o k-a /$} \\
\hline Cycle 2: & golov-O & lom-ok-a & $\mathrm{b}^{\mathrm{j}}$ etón-o & $\mathrm{m}^{\mathrm{j}} \mathrm{e}-\mathrm{a}-\mathrm{l}-\mathrm{ok}-\mathrm{a}$ \\
\hline BAP & gólov-O & lóm-ok-a & $\mathrm{b}^{\mathrm{j}}$ etón-o & $m^{j} e \int-a ́-l-o k-a$ \\
\hline Cycle 3 & \multicolumn{2}{|c|}{ gólovolómoka } & \multicolumn{2}{|c|}{$\mathrm{b}^{\mathrm{j}}$ etónom ${ }^{\mathrm{j}} \mathrm{e} a ́ l o k a$} \\
\hline Postcyclic: vowel (yer) deletion & \multicolumn{2}{|c|}{ gólovolómka } & \multicolumn{2}{|c|}{$\mathrm{b}^{\mathrm{j}}$ etónom ${ }^{\mathrm{j}} \mathrm{e} a ́ l k a$} \\
\hline Deaccenting of non-head (optional) & \multicolumn{2}{|c|}{ golovolómka } & \multicolumn{2}{|c|}{ b $^{\mathrm{j}}$ etónom ${ }^{\mathrm{j}} \mathrm{e} a \mathrm{lk}_{\mathrm{k} a}$} \\
\hline Vowel reduction & \multicolumn{2}{|c|}{ gələvılómkə } & \multicolumn{2}{|c|}{ bjitónəmijifálkə } \\
\hline
\end{tabular}

This account gets some things right. First of all, it correctly assigns stress in right-hand stems:

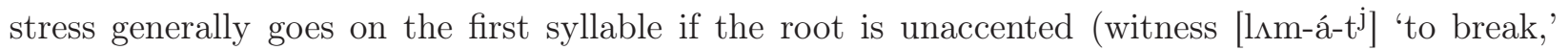
cf. [ $\left[\mathrm{b}^{\mathrm{j}}\right.$ égət $\left.^{\mathrm{j}}\right]$ 'to run'), and it is correctly assigned to the accented verbal thematic suffix /-á/ in [mjifálkə]. Pattern $\mathrm{C}$ stems, such as /golov-/, also receive stress on the first syllable by BAP, and this seems to find some confirmation from grammaticality judgments of native speakers: they prefer no secondary stress in this stem, but if one is present, the optimal position is on the first syllable (see Section 2.2). A parallel OT analysis that incorporates a weak initial default and preservation of lexical accent should be able to get the same result, however (see, for example, Revithiadou 1999 and Section 2.2.3). The account also correctly predicts that right-hand stems should have accent

\footnotetext{
${ }^{10}$ A similar point is explored at length in Roon (2006), who discusses the predictions of Revithiadou's (1999) analysis for compound stress.
} 
in the same location as free-standing words, if such words exist, since the compound's head stem is evaluated in much the same way as the free-standing word (see Roon 2006 for an OT analysis).

The cyclic analysis runs into a few problems, however. First of all, it has trouble with the lexical component of the descriptive generalization for compound stress: the realization of accent on the left-hand root depends on whether it is of Pattern A (Yoo 1992; Gouskova \& Roon 2008). Post-lexical deaccenting cannot discriminate between Pattern $\mathrm{C}$ stems, whose stress is assigned by BAP, and lexically accented Pattern A stems. The deaccenting rule would thus have to be sensitive to whether the accent was introduced by rule or not - in other words, it would have to work like faithfulness. The alternative to this analysis would be to not assign accent by BAP until the postcyclic stratum, and then assign it optionally (perhaps only to low-frequency words, and only if clash can be satisfied). This move, however, misses the very point of a cyclic analysis - indeed, it is not really a cyclic analysis but a derivational clone of the parallel OT anlaysis, since all of the accenting is resolved in the same stratum.

Another challenge for the cyclic analysis is the observation that Pattern B and C stems behave the same in compounds: by default, they do not have secondary stress. In Melvold's analysis, Pattern B stems have an underlying floating accent, which shifts onto the suffix if there is one. These stems are therefore predicted to surface with accent on the linker vowel. This practically never happens - the only context where the linker is stressed is in low-frequency compounds formed by vowelless (yer) stems, such as [ $\mathrm{l}^{\mathrm{j}} \mathrm{d}$-ò-əbrəzəvánijə] 'ice formation' (recall the examples in 16). In such stems, the linker is stressed because it is the only vowel, not because stress belongs there by default phonologically. Other than these contexts, stress does not fall on the linker - not even in cases where clash is not an issue (see Section 2.2.3). Melvold's theory of lexical accent includes some mechanisms that could get around this incorrect prediction. For example, the linker could be promoted to the status of dominant unaccented suffix. As such, it would be able to trigger the initial default and override lexical accent on the stem without necessarily attracting stress onto itself. There is no way, however, to get initial stress in Pattern B stems without also destroying the results for the equally accented Pattern A stems.

It should be noted that the accentual properties of Pattern B stems in derivational morphology remain poorly understood. Recessive unaccented suffixes such as the nominalizer $/-n^{\mathrm{j}} \mathrm{ik} /$ cause Pattern B stems to surface with accent on the last syllable of the root, not on the suffix, though there are some exceptions. These have final stress and follow Pattern B themselves (see 26). As far as I know, no existing account explains the behavior of suffixes like $/-n^{\mathrm{j}} \mathrm{ik} /$ in Pattern B words. They are mentioned in Melvold's discussion, but not analyzed. Revithiadou (1999) suggests that this affix is a clitic, so the stem is its own prosodic word. While this explains the stress facts, it is inconsistent with the behavior of clitics in voicing (see Section 3.1). An alternative that might work better is that these stems are faithful to the stress pattern of the unaffixed form, which can be formalized in Output-Output faithfulness terms (see Benua 1997 for a very similar analysis of English stress). ${ }^{11}$ Whichever analysis turns out to be correct, it is clear that the behavior of Pattern

\footnotetext{
${ }^{11}$ Alderete (1999b) attributes the pre-accenting behavior of this suffix to the post-stem default, which is violated
} 
B stems in derived nouns does not follow straightforwardly from the premises of the cyclic analysis.

(26) Pattern B stems and unaccented recessive suffixes

\begin{tabular}{|c|c|c|c|}
\hline stól ${ }^{\mathrm{j}}-\mathrm{n}^{\mathrm{j}} \mathrm{ik}$ & 'table waiter (archaic)' & stól, sıtl-á, st $\Lambda$ l-í & 'table' \\
\hline $\mathrm{lj}_{\mathrm{j}}^{\mathrm{id}}-\mathrm{n}^{\mathrm{j}} \mathrm{i} \mathrm{k}$ & 'glacier' & $\mathrm{l}^{\mathrm{j}} \mathrm{ot}, \mathrm{l}^{\mathrm{j}} \mathrm{d}-\mathrm{a}, \mathrm{l}^{\mathrm{j}} \mathrm{d}-\dot{\mathrm{i}}$ & 'ice' \\
\hline $\mathrm{p}^{\mathrm{j}} \mathrm{iró}_{3}-\mathrm{n}^{\mathrm{j}} \mathrm{ik}$ & 'pie maker' & 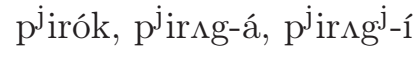 & 'pie' \\
\hline tıpór-n $\mathrm{n}^{\mathrm{j}} \mathrm{k}$ & 'axe maker' & tıpór, təp $\Lambda$ r-á, təp $\Lambda$ r-ú & 'axe' \\
\hline
\end{tabular}

To summarize, the cyclic analysis brings some insights to the phonology of primary stress in compounds, but it cannot account for all the aspects of secondary stress assignment. Most importantly, because this rule-based analysis does not have a mechanism like faithfulness, it cannot capture the generalization that lexically accented Pattern A stems are more likely to surface with secondary stress than stems with alternating stress (Patterns B and C).

\subsection{More on $\mathrm{STEM} \rightarrow \mathrm{PROM}$ and a recursive prosodic word alternative}

The analysis in Section 2.2 introduced a new constraint, STEM $\rightarrow$ PROM, which makes a direct reference to morphology in determining stress placement. This is not an unprecedented move (Alderete 1999b; Revithiadou 1999; Fitzgerald 2001), but it does assume a more direct access to morphological structure than some theories. Allowing phonological constraints to have access to morphological structure could have some problematic consequences, familiar from work on the syntax-phonology interface (Zec \& Inkelas 1990). Direct interface constraints have been proposed in the context of some theories, however - for example, Smith's (2002) theory of positional augmentation. This theory posits that prominent positions should be associated with prominence-enhancing features, such as stress. Positional prominence comes in a variety of forms in this theory, just as in Positional Faithfulness of Beckman (1998), but one important distinction is between roots, which are prominent, and functional elements, which are not. The theory includes constraints such as HAVESTRESS/Root, which requires that a syllable associated with the root bear stress. Smith surveys a number of languages that require their roots to be stressed. STEM $\rightarrow$ PROM is an extension of this theory.

Prosodic phonology presents an alternative to my analysis. Under the most restrictive view, only morphological edges are visible to morpho-phonological alignment constraints, which could be argued to be the only phonological constraints that can make reference to morphological edges (Selkirk \& Shen 1990; Selkirk 1995; McCarthy \& Prince 1993b). The interaction of these constraints determines where the edges of prosodic words are in relation to morphological edges, and the rest of the phonology makes reference only to prosodic word edges, not to morphological constituency. ${ }^{12}$

minimally in derived words. Under the assumptions of this analysis of Russian, Pattern C words are underlyingly accented on the first syllable, but the absence of second- and third-syllable stresses in this class is unexplained. More importantly, dominant unaccented suffixes that impose an initial default on all roots, such as /-en ${ }^{\mathrm{j}} /$, do not receive an analysis at all.

${ }^{12}$ The relevant edges may be defined in terms of the phase (Marantz 2008), though which syntactic derivations introduce phases is still an open question. 
One version of such an analysis would call on recursive prosodic word structure. Each root would then project a stem whose edges are aligned with a prosodic word. Two-root compounds may form two prosodic words, nested inside a larger prosodic word, provided this does not create a stress clash and require inserting a stress. Stress is fully culminative under this analysis, so ENDRULE-L is undominated - there is exactly one foot per prosodic word.

(27) Alternative analysis: recursive prosodic words

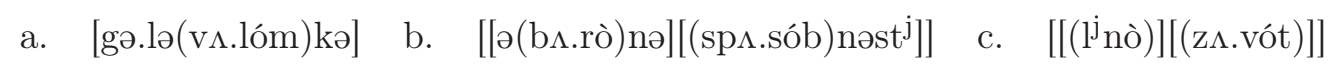

A virtue of this analysis is parsimony: it makes use of prosodic recursion, which is arguably needed for other things. For example, recursive prosodification is one of the four options available crosslinguistically for clitics in Selkirk's (1995) theory (see 28). This theory achieves some representational economy in that it requires no reference to the clitic group, a special prosodic level intermediate between the prosodic word and the phonological phrase (Nespor \& Vogel 1986; Hayes 1989; Kabak \& Vogel 2001).

(28) Prosodification options for clitics
a. affixal: $\quad\left[{ }_{P W d}\right.$ clitic $[P W d$ word $\left.]\right]$
b. internal: $\quad[P W d$ clitic word $]$
c. free: $\quad\left\{P_{P} P \operatorname{clitic}[P W d\right.$ word $\left.]\right\}$
d. prosodic word: $[P W d$ clitic $][P W d$ word $]$

Both clitics and compounds have been used as evidence for the clitic group as a separate prosodic constituent, but clitic groups have had a controversial status in the history of phonological theory (Kabak \& Revithiadou 2008; Ito \& Mester 2009). It is clear that clitics are prosodically special, but to ascribe the special prosodic level of "clitic group" to them simply names the problem without solving it. Ideally, the special status of clitics should come from more general principles, not from a special prosodic level — as it does in theories such as Selkirk (1995). The clitic group also has some suspicious properties. For example, practically every other level of prosodic structure can be parsed without violating exhaustivity, in the canonical case. On the other hand, the clitic group, where it is present non-vacuously, always requires violating exhaustivity. Finally, it is not at all clear that the phonology of compounds and the phonology of clitics share enough in common for the clitic group to be the account for both.

Recursion also has problems. First of all, it seems that the word is the lowest (and possibly the only) level of prosodic structure at which recursion is even possible (McCarthy 2007, Section 3.2.2), but it is not clear why recursion should be limited in this way. It is difficult to limit recursion to prosodic words on principle, without stipulation. Structural recursion at the prosodic word level also does not necessarily explain why non-recursive and recursive structures pattern differently. If the phonology of prosodic words and their boundaries is governed by alignment constraints, as is commonly assumed, then how are outer and inner edges of prosodic words distinguished? Ito \& 
Mester (2009) propose to differentiate between maximal and minimal projections of a small number of prosodic categories, eliminating reference to the clitic group; but this still requires an extra device to replace the clitic group. Recursion alone is not doing the job here. Kabak \& Vogel (2001) note that a simple recursive prosodic word analysis lacks the power to capture domain restrictions on various rules in Turkish. In Russian, positing recursive prosodic words as part of an account of stress realization would require distinguishing between inner and outer prosodic words, but even with that distinction, the analysis would run into an insurmountable body of evidence against prosodic word boundaries inside compounds.

To settle these issues decisively, we need evidence from a number of detailed studies of individual languages. The next section presents such a study of Russian. I look at the rules of Russian that make reference to prosodic word edges. These rules provide clues to the prosodic structure of clitics

as well as compounds. I show that when all of these rules are considered carefully, neither clitic groups nor recursion are necessary. My account makes reference only to prosodic words, feet, and phonological phrases. The main point to take away from this discussion is that sometimes, what looks like recursive prosodic structure or an intermediate level between phonological words and phrases is neither.

\section{The phonology of boundaries in Russian}

In this section, I show that there is no prosodic word boundary inside subordinating compounds in Russian - they constitute single prosodic words. The argument can be sketched out in skeletal form as follows. Suppose that, contrary to my analysis, there are prosodic word boundaries inside subordinating compounds. Under the usual assumptions of the Generalized Alignment approach to phonological constituent boundaries (Selkirk \& Tateishi 1988; McCarthy \& Prince 1993a; Selkirk 1995), each PWd boundary should (at least in the default case) coincide with some morphological boundary. There are several plausible locations. First, the boundary could lie at the right edge of the first, non-head stem, before the linker vowel (see 29a). Alternatively, the boundary could lie at the left edge of the head stem (29b). I will show that the first structure is inconsistent with devoicing patterns, and the second structure is inconsistent with vowel reduction.

(29) Hypothetical locations for prosodic word boundaries in the recursive PWd analysis

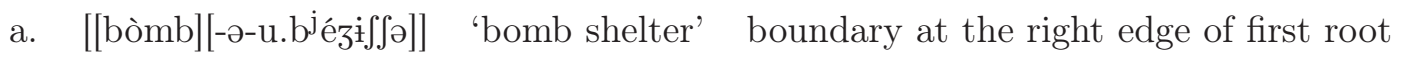

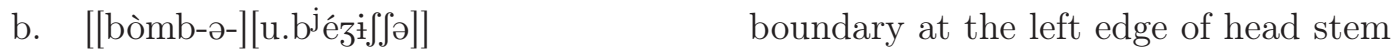

I start by presenting some background on the phonology of prosodic word boundaries in Russian. I will follow the traditional mode of argumentation in work on word prosody (see, for example, the various contributions to Hall \& Kleinhenz 1999): we start with unambiguous cases where morphological and phonological words are perfectly aligned, and then see if the boundary rules work the same way for these cases and the more ambiguous cases such as compounds and clitics. I will show 
that these diagnostics fail to identify a word boundary inside compounds.

\subsection{Voicing neutralization}

One of the best-known features of Russian phonology is the restricted distribution of voicing in its obstruents (Hayes 1984; Kiparsky 1985; Padgett to appear; Petrova et al. 2006, and others). ${ }^{13}$ As shown in (30), Russian obstruents contrast for voice before sonorants, but the contrast is lost in wordfinal codas. Underlyingly voiced obstruents devoice word-finally. In sequences of obstruents, voicing must agree; this requirement is enforced by regressive assimilation. Again, the key generalization is that the obstruent in pre-sonorant position is faithful to its voicing specification. (Many of the vowels in the examples below show quality changes; vowel reduction is discussed in detail in Section

(30) Russian devoicing and assimilation

a. Contrast word-initially and prevocalically, lost word-finally

\begin{tabular}{|c|c|c|c|c|c|}
\hline /gaz/ & gás & 'gas (nom. sg.)' & /gaz-a/ & gá.zə & gen. sg. \\
\hline / kos/ & kós & 'braid (gen. pl.)' & /kos-a/ & kı.sá & nom. pl. \\
\hline$/ \mathrm{st}^{\mathrm{j}} \mathrm{ep}^{\mathrm{j}} /$ & $s t^{j} e^{j}$ & 'steppe' & $/ \mathrm{zd}^{\mathrm{j}} \mathrm{es}^{\mathrm{j}} /$ & $\mathrm{zd}^{\mathrm{j}} \mathrm{és}^{\mathrm{j}}$ & 'here' \\
\hline$/ \mathrm{zv}^{\mathrm{j}} \mathrm{ezd} /$ & $\mathrm{zV}^{\mathrm{j}}$ óst & 'star (gen. pl.)' & $/ \mathrm{zv}^{\mathrm{j}} \mathrm{ezd}-\dot{\mathrm{i}} /$ & $z^{j}{ }^{j}$ zdi & nor \\
\hline
\end{tabular}

b. Assimilation in obstruent-obstruent clusters but contrast before sonorants

\begin{tabular}{|c|c|c|c|c|c|}
\hline$/ \mathrm{sn}^{\mathrm{j}} \mathrm{eg} /$ & $\mathrm{sn}^{\mathrm{j}} \mathrm{ek}$ & 'snow' & /znak/ & znak & 'sign' \\
\hline /ot-p $\mathrm{p}^{\mathrm{j}} \mathrm{it}^{\mathrm{j}} /$ & $\Lambda t \cdot p^{j} i^{j}{ }^{j}$ & 'to take a sip' & $/$ ot $\mathrm{b}^{\mathrm{j}} \mathrm{it}^{\mathrm{j}} /$ & $\Lambda d \cdot b^{j} \operatorname{it}^{j}$ & 'to fight off' \\
\hline /ot-l ${ }^{j} i^{j}{ }^{j} /$ & $\Lambda \mathrm{t} . \mathrm{l}^{\mathrm{j} i \mathrm{t}^{\mathrm{j}}}$ & 'to pour off' & /ot-dat ${ }^{\mathrm{j}} /$ & $\Lambda$ d.dát j & 'to give away' \\
\hline /pod-kopat $\mathrm{j} /$ & pət.kıpát ${ }^{j}$ & 'to dig some' & $/ \operatorname{pod}_{-} \mathrm{l}^{\mathrm{j}} \mathrm{it}^{\mathrm{j}} /$ & $\mathrm{p} \Lambda \mathrm{d} . \mathrm{l}^{\mathrm{j}} \mathrm{it}^{\mathrm{j}}$ & 'to pour some more' \\
\hline
\end{tabular}

Assimilation always applies inside the prosodic word, and final devoicing always applies at the ends of prosodic words. Setting compounds aside for the moment, a prosodic word in Russian is composed of a root plus any prefixes, prepositions, and suffixes. Some prepositions ( $s$ 'with,' $v$ 'in' and $k$ 'to') consist of single consonants and cannot even head their own syllables, and even those that are syllabic ([pod] 'under', [nad] 'over', and [bez] 'without') are usually grouped into prosodic words with lexical words that follow them. They are normally unstressed (see 31), though in some cases they even pull stress off the lexical words they follow, as in /na smex/ [ná $\mathrm{sm}^{\mathrm{j}} \mathrm{ix}$ ] '(exposed) to ridicule' (Ukiah 1998). Given this distribution of voiced obstruents, the sequence of a voiceless obstruent before a voiced one is a good diagnostic for a prosodic word boundary (Padgett to appear). Likewise, devoicing (outside of the assimilation context) is a diagnostic for PWd-final position:

\footnotetext{
${ }^{13}$ The sources cited here vary quite a bit in how they characterize the Russian facts. I describe the facts based on my own dialect, which is like that described by Padgett to appear. I leave out the well-known complications involving $/ \mathrm{v} /$, which are irrelevant to the problem at hand and which are thoroughly covered in Padgett's work.
} 


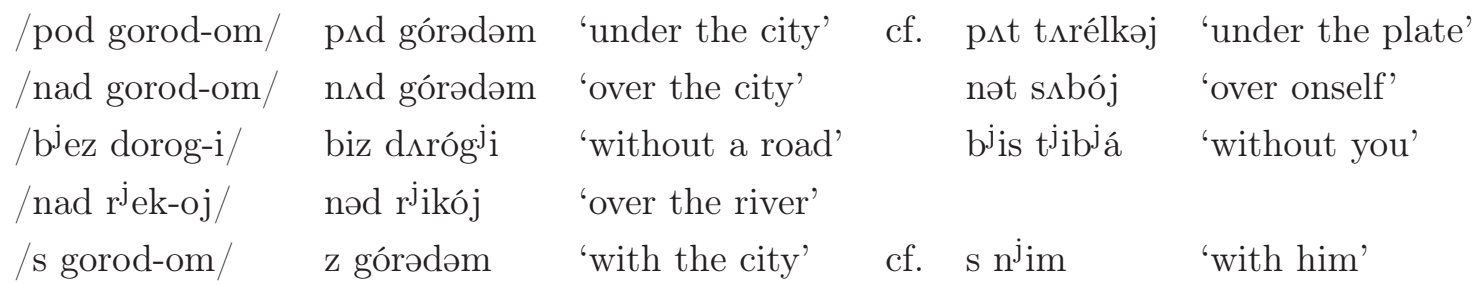

(32) Devoicing and lack of assimilation between words

\begin{tabular}{|c|c|c|}
\hline$/ \mathrm{p}^{\mathrm{j}}$ irog ostil $/$ & $\mathrm{p}^{\mathrm{j} \text { irók } \Lambda \text { stíl }}$ & 'the pie cooled off' cf. $\mathrm{p}^{\mathrm{j} \text { ir } \Lambda \text { gá }}$ \\
\hline$/ \mathrm{p}^{\mathrm{j}}$ irog razm ${ }^{\mathrm{j}} \mathrm{ak} /$ & 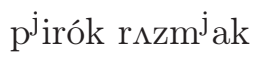 & 'the pie got soggy' \\
\hline /gorod gorjit/ & górət $\mathrm{g} \Lambda \mathrm{r}^{\mathrm{j}}$ ít & 'the city is burning' \\
\hline /pomog drugu/ & p^mók drúgu & 'helped a friend' \\
\hline$/ \operatorname{pomog} n^{\mathrm{j}} \mathrm{in}^{\mathrm{j}} \mathrm{e} /$ & pımók $n^{j_{i n}}{ }^{j}$ & 'helped Nina' \\
\hline
\end{tabular}

There is another twist to how prosodic boundaries condition voicing alternations. As noted by Padgett (to appear), Hayes (1984), and Kiparsky (1985), proclitics (i.e., prepositions) act as though they are word-internal for the purposes of devoicing and assimilation, but enclitics occupy an intermediate role. Devoicing applies before enclitics as if at a word boundary, but voicing assimilates across the enclitic boundary, suggesting that the domain of voicing assimilation is slightly different from the domain of devoicing. The generalization is as follows:

\section{Voicing Agreement in Russian:}

Sequences of obstruents have to agree in voicing as long as they are not separated by the left boundary of the prosodic word.

(34) Devoicing and assmilation with enclitics

$/$ gorod $\mathrm{l}^{\mathrm{j}} \mathrm{i} / \quad$ górət $\mathrm{l}^{\mathrm{j}} \mathrm{i} \quad$ 'city+yes/no particle'

/gorod bi/ górəd bì 'city+irrealis particle'

/gorod ze/ górəd $3^{\grave{i}} \quad$ 'city+discourse particle'

/moroz to/ mırós tə 'frost+discourse particle'

Padgett argues (to appear: fn. 3) that the correct analysis of these facts must make reference to prosodic positions. He suggests that the domain of voicing agreement is the Clitic Group (Nespor \& Vogel 1986), whereas the domain of devoicing is PWd-final. I largely adopt the spirit of this analysis, though my analysis handles edge asymmetries without reference to the Clitic Group level (see Section 2.4). Instead, I assume that Russian enclitics adjoin to the phonological phrase, as in Selkirk's (1995) treatment of English function words. The analysis is developed in the next section.

In compounds, voicing neutralization treats the last consonant of the first stem as if it is not separated by a prosodic word boundary from the following vowel. The linking vowel behaves like 
any word-internal sonorant: it does not condition devoicing (see 35). This pattern is what we would expect if the linking vowel is in the same prosodic word as the preceding obstruent. Crucially, voicing is not sensitive to the presence of secondary stress, as shown in the last two examples. ${ }^{14}$

(35) Voicing in compounds

\begin{tabular}{|c|c|c|c|}
\hline$/ \mathrm{l}^{\mathrm{j} e d-o-k o l} /$ & $\mathrm{j}^{\mathrm{j}} \mathrm{i} . \mathrm{d} \Lambda . k o ́ l$ & 'ice breaker' & cf. $\mathrm{l}^{\mathrm{j}}$ ót 'ice (nom. sg.)' \\
\hline /vod-o-napor/ & və.də.n^.pór & 'water pressure tower' & cf. vót 'water (gen. pl.)' \\
\hline /golov-o-lomka/ & gə.lə.vı.lóm.kə & 'puzzle' & cf. gnlóf 'head (gen. pl.)' \\
\hline /bomb-o-ubj $3^{\mathrm{j}} \mathrm{f} \int \mathrm{e} /$ & bòm.bə.u.b bé.zi. $\iint ə$ & 'bomb shelter' & cf. bómp 'bomb (gen. pl.)' \\
\hline
\end{tabular}

To summarize, in Russian, sequences of obstruents assimilate in voicing inside prosodic words, but never across two prosodic words. The right and the left boundaries of the prosodic word differ: assimilation is blocked at the left edge of the prosodic word but allowed on the right. Devoicing applies at the right edge of a prosodic word only. Compounds behave as if they do not contain a PWd boundary between the final consonant of the left-hand stem and the linker vowel. This rules out the first recursive Pwd analysis discussed at the beginning of Section 3, [[root $\left.1_{P w d}\right]$-[linker$\left.\left.\operatorname{root} 2_{P w d}\right]_{P w d}\right]$. My own analysis of voicing in compounds is developed next.

\subsection{Analysis of voicing neutralization}

The main outlines of the phonological analysis of devoicing and assimilation in OT are fairly uncontroversial, though there is some debate as to the details. Lombardi (2001) presents convincing typological arguments that the proper analysis of voicing neutralization requires a general constraint against voicing rather than a positional markedness constraint against voicing in codas or wordfinally (cf. Ito \& Mester 2003). The prohibition on voicing applies to all positions equally, but pre-sonorant consonants are protected by a special licensing-by-cue constraint (Steriade 1999). I will follow Padgett (to appear), who defines the constraint as relativized to obstruents followed by

\footnotetext{
${ }^{14}$ In truncated compounds, which are formed by concatenating truncated words from phrases, voicing behaves similarly. While the morphology of these is quite different from that of subordinating (linking vowel) compounds, they are similar in also allowing for secondary stress (Gouskova \& Roon 2008), and the realization of secondary stress is also sensitive to frequency (though not blocked by stress clashes). These compounds appear to follow the same pattern as subordinating compounds in terms of voicing: we see voicing assimilation at the juncture. Examples: /zav-sklad/ [zàfsklát] 'warehouse manager,' /pol it- $\mathrm{b}^{\mathrm{j}} \mathrm{uro} /$ [p$\Lambda \mathrm{j}^{\mathrm{j}} \mathrm{i} \mathrm{db}^{\mathrm{j}}$ uró] 'politburo (gov’t body),' /gaz-prom/ [gàspróm] 'Gazprom (oil company name),' / $\mathrm{d}^{\mathrm{j}}$ et-dom/ [d èddóm] 'orphanage.' Kuznetsova (2006) cites a couple of examples of devoicing in presonorant position, but both involve a single truncation, "glav", ending in /v/: /glav-riba/ [glàfríbə] 'name of a fishery office (main+fish),' /glav-energo/ [glàfinérgə] name of an energy company (main+energy). There is more to the story here, however, since other consonants do not devoice in the same context: $/ \mathrm{m}^{\mathrm{j}}$ ed-inst $^{\mathrm{j}}$ itut $/\left[\mathrm{m}^{\mathrm{j}} \mathrm{èdinst}^{\mathrm{j}}\right.$ itút]

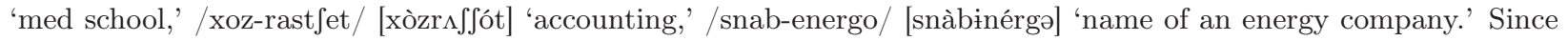
the behavior of $/ \mathrm{v} /$ in devoicing is known to be problematic, I conclude that devoicing is the exception rather than the rule - the default pattern is for obstruents to retain voicing in presonorant position in truncated and in subordinating compounds. It is likely that secondary stress in truncated compounds can, therefore, receive the same analysis as subordinating compounds.
} 
sonorants in the same phonological word. ${ }^{15}$

(36) Constraints for voicing neutralization (after Lombardi 1999; Padgett to appear; Petrova et al. 2006)

*VoICE: assign a violation mark for each obstruent specified as voiced

AGREE: obstruent clusters agree in voicing

IDENTPRESON(voice): For every consonant $\mathrm{C}$ immediately preceding a sonorant $\mathrm{S}$ such that $\mathrm{C}$ and $\mathrm{S}$ are dominated by the same prosodic word, assign a violation mark if $\mathrm{C}$ is not faithful to its underlying voicing specification ${ }^{16}$

IDENT(voice): Assign a violation mark for every segment that is not faithful to its underlying specification for voice

In Russian, the constraints are ranked $\{$ IdentPreSon(voice), Agree $\} \gg *$ Voice $\gg$ Ident(voice), as shown in (37). Under this analysis, voicing is lost in word-final codas (37a) but not in presonorant codas or any other presonorant positions (37b, c, d). This is a key difference between languages like Russian and German. Furthermore, since AGREe only applies to sequences of obstruents, there will be a contrast in presonorant position $(37 \mathrm{~b}, \mathrm{~d}, \mathrm{e})$. To satisfy IDENTPRESON, voicing assimilation must be regressive in obstruent clusters, as shown in (37e): the last (i.e., pre-sonorant) consonant retains its underlying specification and determines the voicing of the entire cluster.

(37) Voicing neutralization in Russian

\begin{tabular}{|c|c|c|c|c|c|}
\hline inputs & winner loser pairs & IDENTPRESON & AGREE & *VOICE & IDENT \\
\hline a. $/ \mathrm{sn}^{\mathrm{j}} \mathrm{eg} /$ & $\mathrm{sn}^{\mathrm{j}} \mathrm{ek} \sim \mathrm{sn}^{\mathrm{j}} \mathrm{eg}$ & & i & $\bar{W}$ & $\bar{L}$ \\
\hline b. /znak/ & znak $\sim$ snak & $\bar{W}$ & I & $\mathrm{L}$ & $\bar{W}$ \\
\hline c. /gaz/ & gas kas & $\mathrm{W}$ & 1 & $\mathrm{~L}$ & $\mathrm{~W}$ \\
\hline d. $/ \operatorname{pod}-\mathrm{l}^{\mathrm{j}} \mathrm{it}^{\mathrm{j}} /$ & $\mathrm{p} \Lambda \mathrm{d} . \mathrm{l}^{\mathrm{j}} \mathrm{it}^{\mathrm{j}} \sim \mathrm{p} \Lambda \mathrm{t} . \mathrm{l}^{\mathrm{j}} \mathrm{it}^{\mathrm{j}}$ & $\mathrm{W}$ & 1 & $\mathrm{~L}$ & $\mathrm{~W}$ \\
\hline \multirow[t]{2}{*}{ e. $/$ ot-b $b^{j} \mathrm{it}^{\mathrm{j}} /$} & $\Lambda d \cdot b^{j}{ }_{i t}^{j} \sim \Lambda t \cdot p^{j}{ }^{j} t^{j}$ & $\mathrm{~W}$ & I & $\mathrm{L}$ & $\mathrm{W}$ \\
\hline & $\Lambda \mathrm{d} \cdot \mathrm{b}^{\mathrm{j}} \mathrm{it}^{\mathrm{j}} \sim \Lambda \mathrm{t} \cdot \mathrm{b}^{\mathrm{j}} \mathrm{it}^{\mathrm{j}}$ & & $\mathrm{W}$ & $\mathrm{L}$ & $\mathrm{W}$ \\
\hline
\end{tabular}

Any analysis of these facts should explain what prevents voicing agreement from applying between two prosodic words. The approach I will pursue is that voicing assimilation is actually required in all contexts, even at the boundary between two words, but that spreading is blocked at the left edge of a prosodic word. The justification for this will be familiar from considerations of positional faithfulness and markedness: beginnings of words are the sites of special consideration.

\footnotetext{
${ }^{15}$ While a reference to onset positions alone would be more in line with positional faithfulness theory (Steriade 1995; Beckman 1997), it has long been known that it would now work for cases like Russian (see Padgett to appear and references therein, and more recently Petrova et al. 2006). In Russian, voicing is preserved in pre-sonorant obstruents that are clearly syllabified in coda position, as in /ob-man $/ \rightarrow[\Lambda$ b.mán] 'deceit.' Russian does not allow the cluster [bm] word-initially, and phonotactic constraints are even stricter medially (Steriopolo 2007).

${ }^{16}$ This complex formulation suggests that there is something more going on here, but I will leave the issue for later exploration for now.
} 
In this case, a positional constraint prohibits feature sharing across the left edge of a prosodic word but not elsewhere. The constraint I propose combines some aspects of alignment and some aspects of CRISPEDGe constraints (Kawahara 2007; Pater 2001; Ito \& Mester 1999). In Russian, it would apply to any sequence of obstruents within the same prosodic word but not across prosodic words. A more precise definition of NoStRAdDLing is developed in the appendix (Section 6).

(38) NoStraddling(voice, L, PWd): "Assign a violation for every [voice] feature node shared by segments separated by the left edge of a prosodic word."

NoStraddling dominates Agree:

(39) NoStRAdDLing and lack of voicing agreement across prosodic word edges

\begin{tabular}{|c|c|c|c|c|}
\hline & & NoStradDLING & AGREE & IDENT \\
\hline /gorod gorit/ & [górət][g $\Lambda$ rít] [górəd] $[\mathrm{g} \Lambda$ rít] & $\mathrm{W}$ & $\mathrm{L}$ & \\
\hline /gorod bi/ & $\{$ [górəd]bi $\}$ & & W & $\mathrm{L}$ \\
\hline
\end{tabular}

Making a reference to prosodic word edges allows us to account for the domain of voicing assimilation without appealing to "lexical" and "post-lexical" modules, as in Lexical Phonology and Optimality-Theoretic frameworks that descend from it (Rubach 2000b; Kiparsky to appear; Gribanova 2008). A Lexical Phonology analysis encounters some difficulties, as pointed out by Padgett (to appear, fn. 3): prepositions and enclitics are clearly syntactically independent, yet in an LP analysis, they must be attached in the lexicon in order for devoicing to apply only at the ends of lexical words (see also Marantz 1997 for a similar point about lexicalist theories). Here, I develop a unified prosodic analysis of voicing neutralization in compounds, prepositions, and enclitics that makes no assumptions about the grammatical locus of clliticization and compounding. Notably, this analysis works without appealing to the Clitic Group prosodic level (see Section 2.4).

I posit the following prosodic structure for compounds. Compounds constitute single prosodic words, though those compounds that have secondary stress have more than one foot, departing from the default pattern of one-stress-per-word (Gouskova \& Roon 2008). In the structure assumed for "medical school" below, the boundary of the first foot coincides with the end of the first truncated stem, 'med-'. It has been argued that, suffixes excepted, Russian largely respects morpheme boundaries in syllabification (Zubritskaya 1995; Petrova et al. 2006), though this assumption is not central to my analysis of devoicing.

(40) Prosodic structure for subordinating and truncated compounds

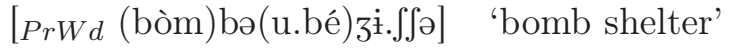

$$
\begin{aligned}
& {\left[\operatorname{PrWd}\left(\mathrm{m}^{\mathrm{j}} \mathrm{èd}\right) \mathrm{in}\left(\mathrm{st}^{\mathrm{j}} \mathrm{itút}\right)\right] \quad \text { 'medical school' }}
\end{aligned}
$$


(41) No devoicing stem-finally in compounds

\begin{tabular}{|c|c|c|c|}
\hline /bomb-o-u-b $\mathrm{b}^{\mathrm{j}} \mathrm{e}-\mathrm{i} \iint-\mathrm{e} /$ & AGREE I IDENTPRESON & *VOICE & IDENT \\
\hline 啄bòm.bə.u. $b^{j}$ é. $z^{\dot{1}} \cdot \iint \partial$ & 1 & & \\
\hline 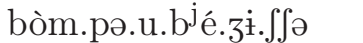 & W & $\mathrm{L}$ & W \\
\hline
\end{tabular}

Recall that enclitics trigger voicing assimilation but do not block devoicing. This is because the right edge of the prosodic word is right before the enclitic, which I take to be dominated by the phonological phrase but not by the prosodic word. Under Selkirk's (1995) theory, this configuration arises when ExHAUstiviTy is dominated by the right alignment constraints. In Russian, Exhaustivity must be ranked below the constraint that requires the right edge of a prosodic word to coincide with the right edge of a lexical word. This rules out a parse where the clitic heads its own prosodic word, as in (44b) as well as prosodic-word-internal cliticization, as in (44c). (Other constraints distinguish $44 \mathrm{~b}$ and $44 \mathrm{c}$, though they are not shown here). I take a lexical word in Russian to be closed off by inflectional morphology — for nouns, the case endings.

(42) Constraints for prosodic parsing in Russian (following Selkirk 1995)

Exhaustivity $(\mathrm{PhP})$ : 'assign a violation mark for every immediate daughter of $\mathrm{PhP}$ that is not a PWd'

$\operatorname{Align}(\mathrm{R}, \mathrm{PWd}, \mathrm{R}, \mathrm{Lex})$ : 'assign a violation mark if the right edge of a prosodic word is not aligned with the right edge of a lexical word.'

$\operatorname{Align}(\mathrm{L}, \mathrm{Lex}, \mathrm{L}, \mathrm{PWd})$ : 'assign a violation mark if the left edge of a lexical word is not aligned with the left edge of a prosodic word.'

(43) Assigning prosodic structure to enclitics: phonological phrase adjuncts

\begin{tabular}{|c|c|c|}
\hline $\operatorname{gorod}_{L e x W d}, \mathrm{j}^{\mathrm{j}} \mathrm{i}$ & $\operatorname{Align}(\mathrm{R}, \mathrm{PWd}, \mathrm{R}, \mathrm{Lex})$ & ExhAustivity $(\mathrm{PhP})$ \\
\hline a. $\quad$ 吗 $\left\{{ }_{P h P}\left[\right.\right.$ górət] $\left.\mathrm{l}^{\mathrm{j}} \mathrm{i}\right\}$ & & $*$ \\
\hline b. $\quad\left\{\right.$ PhP $[$ górət $\left.]\left[\mathrm{l}^{\mathrm{j}} \hat{1}\right]\right\}$ & $* \mathrm{~W}$ & $\mathrm{~L}$ \\
\hline c. $\quad\left\{P_{P h P}[\right.$ górədilj $\left.\mathrm{i}]\right\}$ & ${ }^{*} \mathrm{~W}$ & $\mathrm{~L}$ \\
\hline
\end{tabular}

The failure to include the yes/no enclitic [li] in the same prosodic word as the preceding obstruent explains why devoicing applies here: IDENTPRESON is not relevant to [t], since it is not followed by a sonorant in the same prosodic word. On the other hand, if it were to be followed by a voiced obstruent, it would surface as voiced, since AGREE applies regardless of context and general IDENT is dominated.

Unlike enclitics, proclitics are included in the prosodic word headed by their syntactic host. In order to capture this asymmetry between proclitics and enclitics, Align(L, Lex, L, PWd) must be ranked lower than Exhaustivity $(\mathrm{PhP})$. Now the preposition is included in the prosodic word with the following lexical words: Exhaustivity $(\mathrm{PhP})$ rules out the mirror image of encliticization by dominating ALIGN-L, so lexical word edges need not be demarcated with prosodic word edges (44b), and Align(R, PWd, R, Lex) prevents the clitic from heading its own prosodic word (44c). 
(44) Assigning prosodic structure to proclitics: word-internal parsing

\begin{tabular}{|c|c|c|c|}
\hline /nad $\mathrm{r}^{\mathrm{j}} \mathrm{ek}-\mathrm{oj} /$ & $\operatorname{AligN}(\mathrm{R}, \mathrm{PWd}, \mathrm{R}, \mathrm{Lex})$ & $\operatorname{ExH}(\mathrm{PhP})$ & $\operatorname{Align}(\mathrm{L}, \mathrm{Lex}, \mathrm{L}, \mathrm{PWd})$ \\
\hline a. 鼍 $\{[$ nədrijikój] $\}$ & & & * \\
\hline b. $\quad\left\{\right.$ nət $\left.\left[\mathrm{r}^{\mathrm{j}} \mathrm{ikó} \mathrm{j}\right]\right\}$ & & $* \mathrm{~W}$ & $\mathrm{~L}$ \\
\hline c. $\quad\left\{[\right.$ nàt $\left.]\left[\mathrm{r}^{\mathrm{j}} \mathrm{ikó} \mathrm{j}\right]\right\}$ & $* \mathrm{~W}$ & & $\mathrm{~L}$ \\
\hline
\end{tabular}

Since the obstruent / $\mathrm{d} /$ is in the same prosodic word as the following sonorant, it will not undergo devoicing as required by *VoICE, since it is required to be faithful by IDENTPRESon. This analysis thus explains both how prosodic structure is assigned to Russian enclitics and proclitics and how the voicing neutralization patterns follow from this prosodification. Devoicing is demarcative in Russian because prosodic word boundaries always mark the right edges of lexical words; the immediate consequence of this is that the general constraint against voicing is satisfied in word-final position.

As for compounds, they are prosodified into single prosodic words, even if they have two stresses. The reason for this is that the bound stems in Russian lack lexical word status. A prosodic word boundary is not inserted at the right edge of a left-hand stem in a compound because there is no lexical word boundary there - the compound ends where the inflection appears, i.e., at the right edge of the right-hand (head) stem. The pattern of voicing neutralization in compounds-i.e., voicing assimilation and lack of final devoicing - is completely unsurprising if compounds are prosodified as single prosodic words. The juncture between the two stems of a compound is no different than the juncture between a preposition and a lexical word: neither coincides with a prosodic boundary.

\subsection{Vowel reduction}

\subsubsection{Phonological background}

In this section, I discuss another rule of Russian that is sensitive to prosodic edges: vowel reduction patterns. In Russian, vowels reduce in all unstressed syllables, but reduction works somewhat differently in a syllable that immediately precedes the stressed syllable in the same phonological word. We expect to see different patterns of reduction in the syllable headed by the linker vowel depending on the structure assumed for compounds. As it turns out, reduction patterns in compounds point to an analysis that does not posit a prosodic boundary. I present some experimental evidence to support this conclusion.

The patterns of vowel reduction are as follows (see Avanesov 1968; Crosswhite 1999; Padgett \& Tabain 2005; Bethin 2006). In stressed syllables, Russian contrasts five vowels: ${ }^{17}$

\footnotetext{
${ }^{17}$ There is an orthographic distinction between [i] and [i], but this pair is not truly contrastive because the choice between the vowels depends on the palatalization/velarization features of the preceding consonants. Phonetically, the vowel [i] is actually a diphthong, [ïi] (Padgett 2001), which Padgett (2003) takes as evidence that sequences normally transcribed as [pi] are phonologically [p ${ }^{\mathrm{x}} \mathrm{i}$. See, however, Blumenfeld (2003) and Rubach (2000a), who argue for a phonemic contrast between [i] and [i] in Russian. This issue is peripheral to the main concerns of the article, since the phonemic status of [i] does not bear directly on reduction patterns: both high unrounded vowels are found in unstressed and stressed syllables.
} 
(45) Russian: five-vowel system in stressed syllables

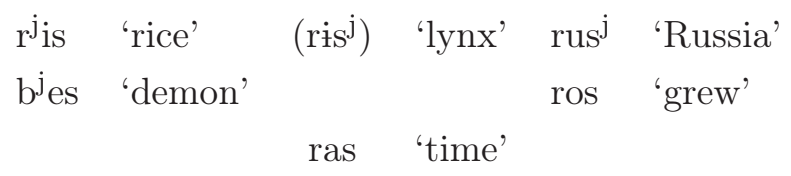

In unstressed syllables, reducing dialects such as the Moscow dialect have only a three-way contrast. There are no mid peripheral vowels: $[\mathrm{e}]$ and $[\mathrm{o}]$ are generally absent in unstressed syllables. The low vowel [a] is also not found in unstressed syllables. While /e/ maps to [i], /o/ and /a/ neutralize to either $[\partial]$ or $[\Lambda]$, depending on position. In immediately pretonic position, both vowels are realized as $[\Lambda]$, whereas $[\theta]$ occurs elsewhere: ${ }^{18}$

(46) Russian vowel reduction by position, standard (Moscow) dialect

\begin{tabular}{|c|c|c|c|c|c|}
\hline /po-kop-a-l-a/ & pəkıpálə & 'has dug (fem)' & /kukuf-k-a/ & kukújkə & 'cuckoo' \\
\hline /za-kaz-a-l-o/ & zəkızálə & 'has ordered (neut)' & $/ \mathrm{pr}^{\mathrm{j}} \mathrm{i}-\mathrm{t} \int \mathrm{in}-\mathrm{a} /$ & pr $^{\mathrm{j}}$ itfínə & 'reason' \\
\hline$/ \mathrm{p}^{\mathrm{j}} \mathrm{er}^{\mathrm{j}} \mathrm{e}-\mathrm{d}^{\mathrm{j}} \mathrm{el}-\mathrm{a}-\mathrm{l} /$ & $\mathrm{p}^{\mathrm{j}} \mathrm{ir}^{\mathrm{j}} \mathrm{d}^{\mathrm{j}} \mathrm{éel}$ & 'has redone (masc)' & $/ \mathrm{v}^{\mathrm{j}}$ etfin-a/ & vi ${ }^{j} t \int i n a ́$ & 'ham' \\
\hline /golov-a/ & gəlıvá & 'head (nom. sg.)' & /golov/ & 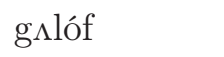 & en. $p$ \\
\hline /golov-í / & góləvi & (nom. pl.) & /golov-o-lom-k-a/ & gələvılómkə & 'puzzle' \\
\hline
\end{tabular}

One noteworthy aspect of the pattern is that the pretonic vowel is not only different in quality from the other unstressed vowels but is also considerably longer; phonetic studies report duration ratios as large as 50\%. Table 1 contains figures from three studies of unstressed vowel reduction in standard Moscow Russian. The first two studies recorded one speaker each; Padgett \& Tabain (2005) recorded nine speakers, but as most of their speakers grew up somewhere other than Moscow, I erred on the side of caution and averaged the measurements from the two Muscovites. Like other researchers, Padgett \& Tabain (2005) found that pretonic vowels are significantly longer than unstressed ones in velarized contexts (though there was no significant difference in palatalized contexts in their data).

\begin{tabular}{|r|c|c|c|}
\hline & Non-pretonic unstressed & Pretonic & Stressed \\
\hline \hline Vysotskij (1973) & $58(49 \%)$ & $80(68 \%)$ & $118(100 \%)$ \\
\hline Barnes (2004) & $25(29 \%)$ & $68(79 \%)$ & $86(100 \%)$ \\
\hline Padgett \& Tabain (2005) & $40(47 \%)$ & $59(59 \%)$ & $85(100 \%)$ \\
\hline
\end{tabular}

Table 1: Vowel lengths (ms.) by position

It is well-known that dialects differ both in the quality and duration of the pretonic vowel (Bethin 2006; Kasatkina \& Shchigel' 1996; Al'muxamedova \& Kul'sharipova 1980; Stroganova 1973). In the standard dialect, which is the focus of this article, the pretonic vowel may or may not be shorter

\footnotetext{
${ }^{18}$ The pretonic reduced vowel is variously transcribed as $[\Lambda]$ (Avanesov 1968), [e] (Barnes 2004; Padgett \& Tabain 2005), and [a] (Crosswhite 1999; Bethin 2006). The exact nature of the vowel is not at issue here: the important point, on which all sources agree, is that the vowel is different from non-prestressed vowels.
} 
than the stressed vowel, but it is considerably longer than other unstressed vowels. Figures 1 and 2 plot average vowel durations (in milliseconds) broken down by stress status from two speakers of the Moscow dialect, a male and a female. The study that produced these data is described in Section 3.4.2.

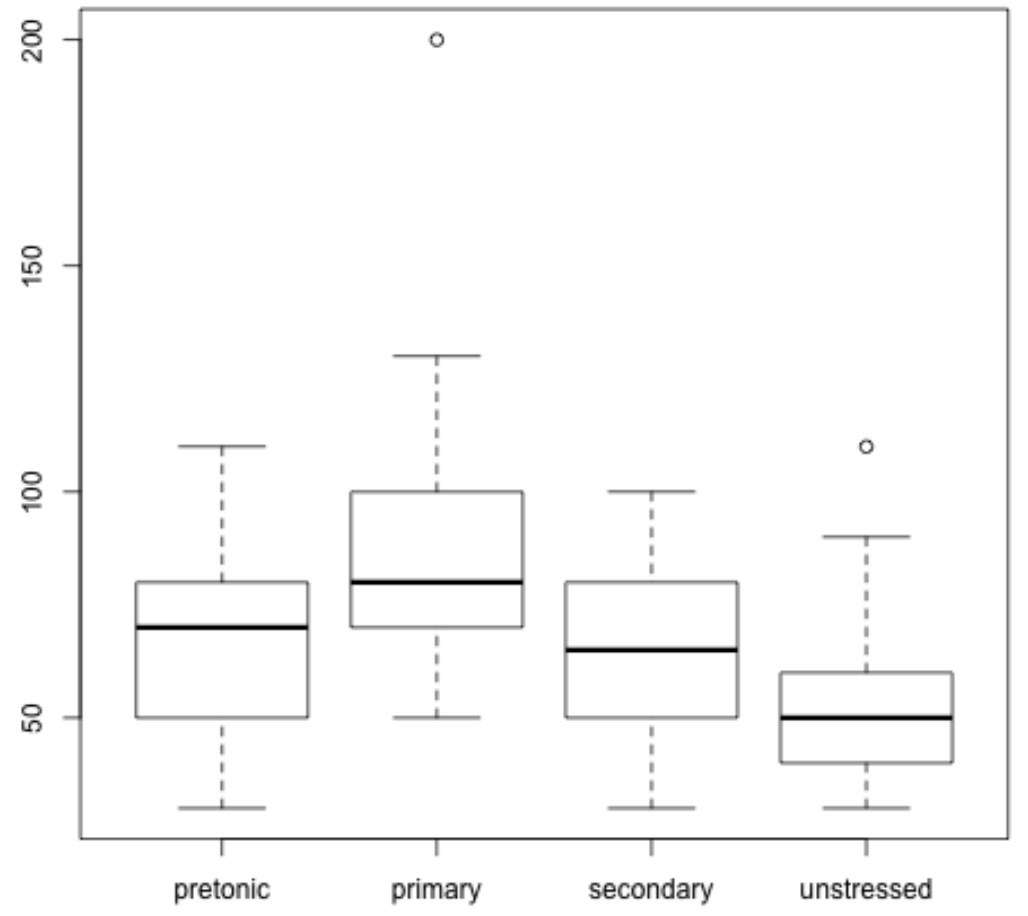

Figure 1: Vowel durations (ms.) by stress position, male speaker 


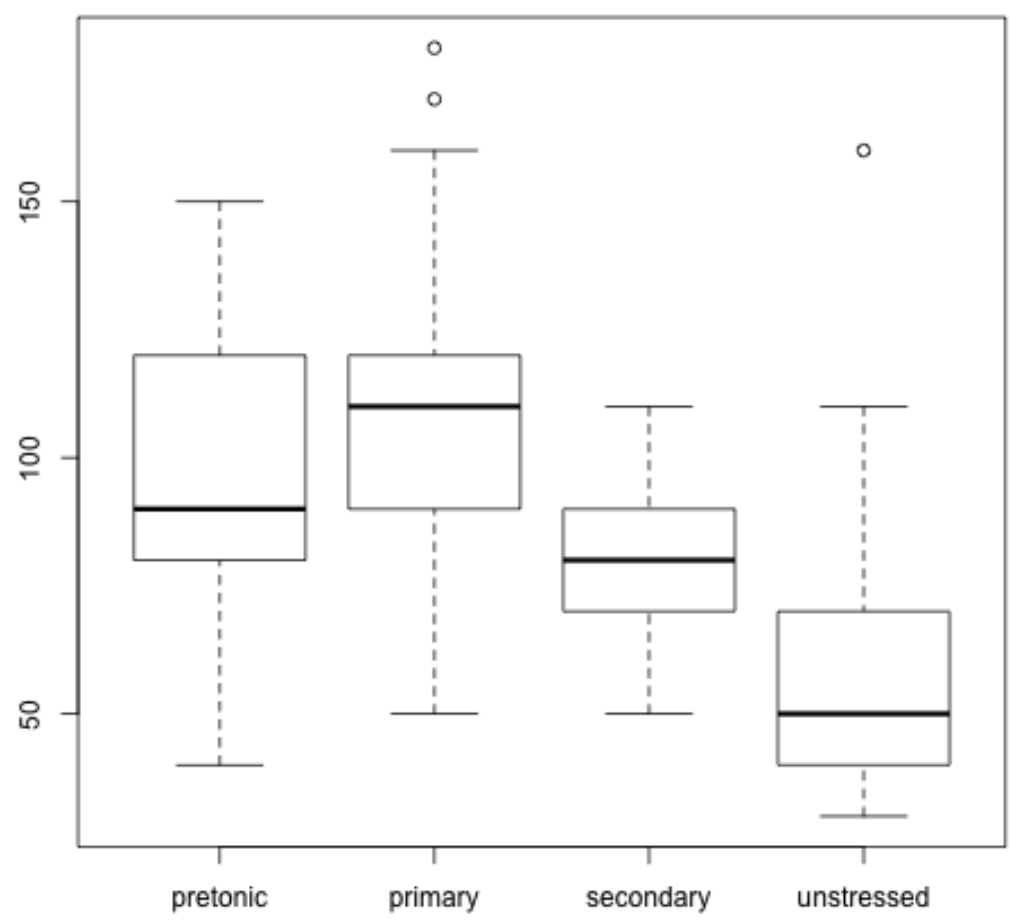

Figure 2: Vowel durations (ms.) by stress position, female speaker

Vowel reduction is a diagnostic for prosodic boundaries in Russian: a vowel followed by a prosodic word boundary cannot be $[\Lambda]$. Thus, the word-final vowel reduces as unstressed and not pretonic, even if the first syllable in the following word is stressed (see 47a,b). As predicted by the analysis of prosodic parsing in Section 3.2, vowels in prepositions reduce as if they are word-internal (see $47 \mathrm{~b}, \mathrm{c})$ :

(47) Vowel reduction and prosodic word boundaries (Gribanova 2009)
a. /mál-o s-káz-an-o/
málə skázənə 'little said'
*málı...
b. /mán-a-ja káj-a/
mánəjə kájə 'semolina porridge'
c. /so v-kus-om/
sıfkúsəm
'with taste'
$*_{\text {sə. . . }}$
d. /do dom-a/
dıdómə
'to the house'

Crosswhite (1999), Alderete (1999b), and Bethin (2006) point to a couple of possible explanations for this pattern. Under Crosswhite's and Alderete's analyses, the pretonic vowel fails to reduce because it is part of an iambic foot. The iambic analysis of Russian has been proposed elsewhere for independent reasons (Halle \& Vergnaud 1987b; Melvold 1990). Assuming that the rest of the unstressed vowels are not part of feet, ${ }^{19}$ this footed position is relatively more prominent, and this

\footnotetext{
${ }^{19}$ Crosswhite assumes that unstressed non-pretonic vowels are not only unfooted but also non-moraic in Russian. This is not a necessary assumption for the analysis to work (see de Lacy 2002 for an alterative that does not rely on representational differences of this sort), but it is ultimately not central to the question of this article.
} 
prominence explains its special phonology. Bethin promotes another explanation: the pretonic vowel is special because of tonal spreading from the following stressed vowel. The two explanations are in principle compatible: the foot could be the domain of tonal spreading. The foot-based analysis also offers an explanation of why reduction is sensitive to prosodic word position: feet cannot be shared between prosodic words for simple tree-theoretic reasons. ${ }^{20}$

An analysis is shown in (48). REDUCE is a cover constraint for all the markedness constraints responsible for reduction patterns inside and outside feet (Crosswhite 1999; de Lacy 2002). REDUCE dominates faithfulness, so reduction is obligatory (see 48b). In two lexical words, the PWd-final vowel cannot show the pretonic reduction pattern because it cannot be footed with the following syllable (as in 48d). Such footing would violate requirements on prosodic word alignment ( ALIGNL(Lex, PWd)), which override any pressure to expand the foot as much as possible, including the familiar constraint FOOTBINARITY "Feet must be binary at the syllabic or moraic level" (McCarthy \& Prince 1986). Nor can the foot itself be moved. Because stress cannot be moved from its lexical position, words with initial stress have degenerate feet (see 48c vs. 48e). This is ensured by ranking NoFlop over FtBin.

(48) Analysis: prosodic words and reduction

\begin{tabular}{|c|c|c|c|c|c|}
\hline /po-kop-á-l-a/ & Align-L(Lex, PWd) & REDUCE & NOFLOP & IDENT[F] & FtBin \\
\hline 实 $[\mathrm{p}$ (kı.pá)lə] & & T & 1 & & 1 \\
\hline [po(kopá)la] & & $\bar{W}$ & I & $\mathrm{L}$ & 1 \\
\hline /mál-o s-káz-an-o/ & & T & 1 & & I \\
\hline c. 噌 $[($ má)lə] [(ská)zənə] & & 1 & 1 & & 1 \\
\hline [(mà)(lı ská)zənə] & W & 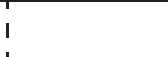 & 1 & & $\mathrm{~L}$ \\
\hline 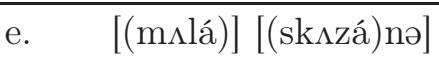 & & 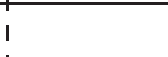 & $\mathrm{W}$ & & $\bar{L}$ \\
\hline
\end{tabular}

With this basic analysis of non-compound words in place, we can now turn to reduction patterns in compounds.

\subsection{Pretonic linking vowels in compounds: an acoustic study}

\subsubsection{Introduction: two hypotheses to test}

Compounds provide a nuanced testing ground for identifying prosodic boundaries. Recall that compounds can surface with or without secondary stress. If secondary stress is indicative of multiple prosodic words, then we expect reduction to apply differently depending on whether secondary stress is present. Conversely, if, as I claim, compounds are always single prosodic words, regardless of

\footnotetext{
${ }^{20}$ While segments (e.g., geminates) can be dominated by more than one distinct higher prosodic constituent, it would be nonsensical for a foot to be dominated by two distinct, non-nested prosodic words. In the case of Russian, this would lead to all sorts of paradoxes: since there is generally only one foot per word, each foot is a head, so an ambi-PWd foot would be the head of both, and one of the words could end up with two heads. Joint domination of this sort must be ruled out in GEN.
} 
whether there is secondary stress or not, then we expect to find no difference in reduction patterns. The alternative hypotheses can be summarized as follows:

(49) Two Prosodic Words Hypothesis: Compound words with secondary stress are parsed into two prosodic words, and words with no secondary stress are single prosodic words. If there is a secondary stress, then there is a prosodic word boundary between the linker and the following stressed vowel, and, therefore, the linking vowel is expected to reduce to [ə]. If there is no secondary stress, then pretonic linkers are expected to reduce to $[\Lambda]$.

(50) Single Prosodic Word Hypothesis: Compound words are single prosodic words whether they have secondary stress or not. There is no prosodic word boundary between the linker and the following stressed vowel regardless of whether the left-hand stem is stressed, and, therefore, it is expected to always reduce to $[\Lambda]$.

The structures below spell out these predictions.

(51) Prosodic structure of compounds under the two hypotheses

\begin{tabular}{|c|c|c|}
\hline & Single Prosodic Word & Two Prosodic Words \\
\hline secondary stress & {$\left[\left(\mathrm{m}^{\mathrm{j}} \mathrm{i} . \mathrm{tà}\right)\left(\mathrm{l}_{\underline{\Lambda}} \cdot \mathrm{r}^{\mathrm{j}} \mathrm{e} \mathrm{e}\right) \mathrm{kə}\right]$} & {$\left[\left(\mathrm{m}^{\mathrm{j}} \mathrm{i}\right.\right.$.tà $\left.) \mathrm{l} ə\right]\left[\left(\mathrm{r}^{\mathrm{j}} \mathrm{e} \mathrm{es}\right) \mathrm{k} ə\right]$} \\
\hline no secondary stress & {$\left[\mathrm{m}^{\mathrm{j}} \mathrm{i} . \mathrm{tə}\left(\mathrm{l}_{\underline{\Lambda}} \cdot \mathrm{r}^{\mathrm{j}} \mathrm{és}\right) \mathrm{k} ə\right]$} & {$\left[\mathrm{m}^{\mathrm{j}} \mathrm{i} . \mathrm{tə}\left(\mathrm{l}_{\underline{\Lambda}} \cdot \mathrm{r}^{\mathrm{j}} \mathrm{és}\right) \mathrm{kə}\right]$} \\
\hline
\end{tabular}

Since the durational differences between pretonic and unstressed vowels are allophonic and potentially difficult to hear for native speakers, I conducted an acoustic study of linker vowels in compounds to test these hypotheses.

\subsubsection{Methods}

Three speakers of Moscow Russian participated in the study: a male in his 50s, a female in her $50 \mathrm{~s}$, and a female in her 30s. The recordings were made in Moscow, in a quiet (though not soundattenuated) room, and the experimenter spoke Russian throughout. The recordings were made on a Marantz PMD660 solid state recorder using a head-mounted Audio-Technica ATM75 microphone. The recordings were digital, recorded at a sampling rate of $44.1 \mathrm{kHz}$.

The speakers read a list of 144 compounds, which they were asked to embed in a frame sentence [nı $\mathrm{p}^{\mathrm{j} i ́ s a n ə ~ — ~} \mathrm{p}^{\mathrm{j}} \mathrm{át}^{\mathrm{j}}$ rás] ' $\mathrm{X}$ is written five times.' The frame was constructed to avoid potential stress clash on the left-hand side of the target word. Each speaker read the list twice. Because of the nature of compound phonology, some words were always produced with secondary stress, others always without, and still others varied by speaker. Sometimes, the same speaker produced secondary stress in only one of the repetitions of a word - this was the case for the male speaker's

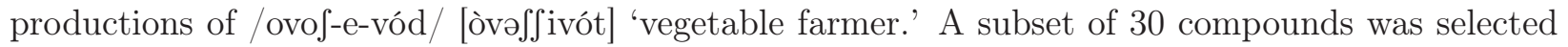
for analysis. Compounds were excluded from analysis if they contained vowel hiatus, vowelless roots, or if the presence of secondary stress was difficult to determine (sometimes this was the case if stress fell on a high vowel). The list of compounds analyzed here is given in Appendix II. 
The files were analyzed in Praat (Boersma \& Weenink 2009) on a Macintosh computer. All vowel intervals were labeled and annotated as to their morphological status (linker vs. not) and stress status: unstressed, pretonic, primary stress, or secondary stress. Boundaries between vowels and consonants were established by examining the waveform and the spectrogram. Vowel boundaries were marked at the onset/offset of clear formant structure (especially F2 and F3) and intensity rises and falls. The duration values were collected by script and imported into R (version 2.9) for statistical analysis.

\subsubsection{Results}

The average duration measurements for pretonic and unstressed linker vowels are shown in Table 2. Figure 3 breaks down the duration of linker vowels in words without secondary stress and with secondary stress.

\begin{tabular}{|l|r|r|r|r|r|r|}
\hline & \multicolumn{3}{|c|}{ No secondary stress } & \multicolumn{3}{c|}{ Secondary stress } \\
\cline { 2 - 7 } & Duration & St. Dev. & N & Duration & St. Dev. & N \\
\hline \hline Pretonic & $92 \mathrm{~ms}$. & 23 & 53 & $80 \mathrm{~ms}$ & 33 & 39 \\
\hline Unstressed & $42 \mathrm{~ms}$. & 20 & 15 & $46 \mathrm{~ms}$ & 13 & 37 \\
\hline
\end{tabular}

Table 2: Duration and formant measurements for linker vowels, pretonic vs. unstressed

These values were compared using a linear model, one-way analysis of variance with duration as the dependent variable; the independent variables were the presence of secondary stress and stress position of the linker vowel (pretonic vs. unstressed). There was a significant main effect of stress position $(\mathrm{F}(1,141)=100.8, \mathrm{p}<.000)$ but not of presence of secondary stress $(\mathrm{F}(1,141)=2.4$, $\mathrm{p}=0.12) .{ }^{21}$ Unstressed linker vowels are reliably shorter pretonic linker vowels, but this difference persists even when secondary stress is present in the left-hand stem. This is shown in Figure 3. The trends in the figure are clear: regardless of the presence of secondary stress, there is a difference between pretonic and unstressed linker vowels, and the difference is of the same kind in both types of words.

\footnotetext{
${ }^{21}$ The residuals are quite high in this model because it leaves out a number of factors that could affect duration, such as speaker, nature of surrounding consonants, number of syllables in the word, and so on. While these factors all affect duration, most of them are essentially irrelevant to the question at hand.
} 


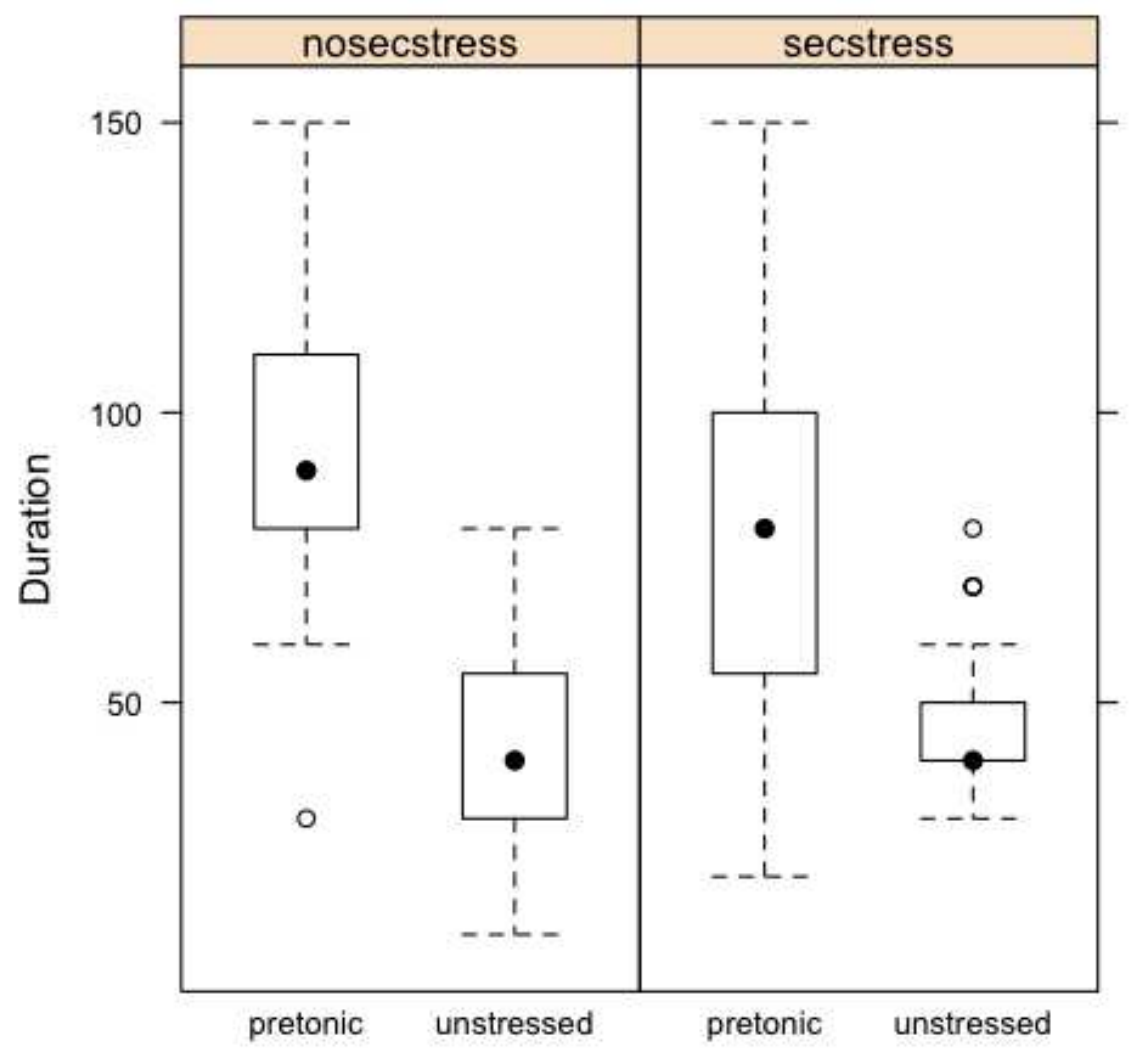

Figure 3: Duration of linker vowels (ms.) in pretonic vs. unstressed position

As can be seen in the figure, pretonic vowels are slightly shorter and considerably more variable in words with secondary stress. This may be due to a kind of "compression" effect that secondary stress has on overall word duration. Words with secondary stress can have two pretonic vowels and two stressed vowels, which are generally long, as opposed to mostly unstressed vowels, which are generally quite short. It is possible that unstressed vowels are shortened as a result so that the overall duration of the word does not increase. The important point here is that even with this degree of variance, pretonic vowels are still almost as long in secondary stress words as they are in words without secondary stress, and they are reliably different from unstressed vowels in both cases.

\subsubsection{Discussion and implications for the phonological analysis}

The results of the acoustic study support the One Prosodic Word Hypothesis: the pretonic linker vowel is footed with the following stressed vowel regardless of whether it is preceded by a secondary stress. The Two Prosodic Words Hypothesis, on the other hand, cannot explain why the linker is longer in pretonic position in words with secondary stress. In the recursive PWd analysis, the linker 
in such words should be PWd-final. If there is a prosodic word boundary between the linker and the following stressed vowel, then it should not lengthen as a function of stress on the following vowel. There are well-known reasons for why prosodic-word-final vowels might lengthen, but rules such as word-final lengthening should presumably affect final vowels in the same way regardless of what follows. If anything, one might expect more across-the-board final lengthening in secondary stress words, not less, since a longer vowel to some extent mitigates stress clash (Nespor \& Vogel 1989).

I conclude from this that the patterns of reduction at the boundary between the stems suggest that there is no prosodic boundary there. The phonological transcription of vowels in compounds is as follows:

(52) Reduction in compounds

a. Pretonic: $[\Lambda]$

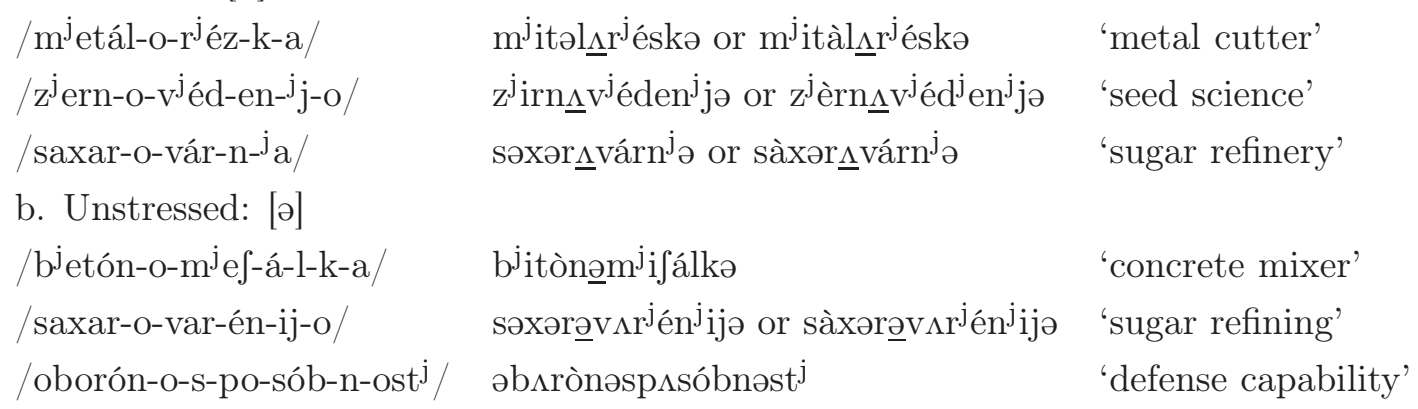

Vowel reduction provides yet another clue to the status of compounds. Even though [o] is normally not found in unstressed syllables, it can occur in word-final syllables, where unstressed, rounded, mid vowels are permitted as long as they are preceded by a vowel (Wade 1992). Words of this type are always indeclinable loanwords. As can be seen in the examples below, these words are not exceptions to reduction in general - only the word-final position is special:

(53) No unrounding in word-final hiatus

\begin{tabular}{|c|c|c|}
\hline rád ${ }^{j}$ io & 'radio' & $*_{\text {radiə }}$ \\
\hline $\mathrm{v}^{\mathrm{j}} \mathrm{d}^{\mathrm{j}}{ }^{\mathrm{i}}$ & 'video' & *vidiə \\
\hline rıdéo & 'rodeo' & *rıdéə \\
\hline $\mathrm{p}^{\mathrm{j}}$ inók $^{\mathrm{j}}{ }_{\text {io }}$ & 'Pinocchio' & ${ }^{*} \mathrm{p}^{\mathrm{j}}$ inok $^{\mathrm{j}}$ iə \\
\hline cf. nók ${ }^{\mathrm{j}}$ iə & 'Nokia' & \\
\hline
\end{tabular}

Some of these words appear in compounds, and there, reduction applies as expected, since they are not word-final:

(54) Unrounding applies in compounds

ràdjiıstántsija 'radio station'

vjidjioprskát 'video rental' 
Kuznetsova (2006) reports that there is some variation in whether the vowel is rounded or unrounded in such words; she speculates that rounding is found in more formal styles. One potential explanation for the lack of unrounding in her data is that her speakers were reading a word list, and in careful reading and more formal speech registers, reduction sometimes fails to apply to medial vowel-[o] sequences (Avanesov 1968:210).

\subsection{Interim summary}

To summarize the results of Section 3, I have presented evidence from Russian juncture phonology to argue that multiple stresses do not diagnose multiple prosodic words in a subordinating compound. There are two possible locations for a prosodic word boundary inside a compound: before the linking vowel or after it. I showed that there cannot be a prosodic word boundary immediately before the linking vowel. Devoicing, which normally applies PWd-finally, fails to apply to the final consonant of the first compound stem, which suggests that there is no PWd boundary between it and the linker vowel that follows. It also cannot be the case that there is a prosodic word boundary immediately after the linking vowel. In vowel reduction, the linker vowel patterns as though it is footed with the following syllable if the syllable is stressed, which requires the two vowels to be in the same prosodic word. ${ }^{22}$

The next section continues the exploration of the phonology of the linking vowel and juncture rules that affect it. There are a few questions that remain. First, we saw in Section 2.2.3 that the linker vowel can be stressed when it follows a vowelless root, but generally, it resists stress - even with post-accenting stems. I argued that the explanation for this is that both the post-accenting stems and the linker vowel are unaccented. The alternative explanation is that the linker is epenthetic. In the next section, I discuss evidence that rules out out the epenthetic account.

\section{More on the phonology and morphology of the linking vowel}

\subsection{Introduction: an epenthetic analysis of stress on linker vowel}

The argument against the epenthetic analysis runs as follows. There are some reasons to think that the linker vowel could be epenthetic; after all, it has been analyzed as such in Greek. The quality of the linker vowel is largely predictable in Russian on the basis of the preceding consonant, as well. There are arguments against the epenthetic analysis, however. First, the vowel surfaces in a

\footnotetext{
${ }^{22}$ There is an additional possibility, which is easy to dismiss. It could be the case that there is a prosodic word boundary in compounds, but it does not abut the linker. Rather, it is before the syllable that contains the linker, as in [[əbıró][n-ə-sp $\Lambda$ sóbnəst $\left.\left.{ }^{\mathrm{j}}\right]\right]$ 'defense capability.' This parsing would explain both the distribution of voicing and the reduction pattern. The root-final consonant is not PWd-final, so it is not expected to devoice, and the linking vowel is in the same prosodic word as the following syllable, so it would reduce as a pretonic vowel rather than a PWd-final vowel, consistent with the pattern described in the phonetic study. While this analysis accounts for the juncture rules, there is a glaring problem with it from the morphophonological standpoint: under this prosodification, there is always a mismatch between the morphological and the phonological structure, and it is never for a sensible reason (e.g., syllable structure requirements - cf. McCarthy \& Prince 1993a). There is simply no reason for this kind of structure.
} 
number of prosodic contexts where epenthesis does not generally happen in Russian, so it is difficult to explain exactly what motivates it. Second, the vowel interacts with the famous yer deletion rule, in a way that casts doubt on the epenthetic analysis.

To start with, let us sketch out the epenthetic linker analysis of stress. There are several ways to formalize the resistance of epenthetic vowels to stress in OT (Alderete 1999a; McCarthy 2007; Broselow 2008). The easiest one to implement within the framework assumed here is Alderete's positional faithfulness constraint, HEAD-DEP.

(55) HeAD-DeP: Every segment contained in a prosodic head in $\mathrm{S}_{2}$ has a correspondent in $\mathrm{S}_{1}$.

'No epenthesis into prosodic heads.' (Alderete 1999a)

This constraint would rule out linker stress even if default stress is post-stem, as long as the linker is epenthetic. The analysis using this constraint is sketched out in (56). The winner has stress on the vowel preceding the linker, which in Alderete's analysis incurs a minimal violation of the gradient Post-STEM constraint: stress is not after the morphological boundary, but it is close to it. Putting stress on the epenthetic vowel would be ideal with respect to POST-STEM, but it fails on the higherranked HEAD-DeP, since the stressed vowel is epenthetic. Not epenthesizing is presumably not an option (note that in this account, the linker is absent from the UR) - for the sake of argument, let us assume that the relevant constraint is *COMPLEX. The cluster in (56c) does indeed approach unpronounceable in Russian, so this analysis has some merit. Since the placement of stress in the winner violates the POST-STEM constraint, even minimally, this analysis also explains why absence of secondary stress would be preferred by default. Root-final accent is expected to surface only in low-frequency stems.

(56) Sketch of an epenthetic analysis

\begin{tabular}{|c|c|c|c|}
\hline /korablj-stroj-én-ij-o/ & $*$ COMPLEX & HEAD-DEP & Post-STEM \\
\hline 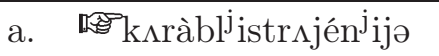 & & & $*$ \\
\hline 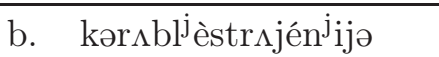 & & $* ! W$ & $\mathrm{~L}$ \\
\hline c. kərəbl $^{j}{ }_{\text {str }} \wedge$ jén ${ }^{j}$ ijə & $* ! \mathrm{W}$ & & \\
\hline
\end{tabular}

While this analysis appears to work, it runs into some difficulties, however. The main problem is justifying the epenthetic analysis of the linker, to which I turn now. If the vowel is epenthetic, then analytic logic requires that its quality be in some way predictable. It should also surface in a phonologically predictable environment. Its epenthetic status also needs to be justifiable given its interactions with other rules. I take these questions up in turn.

\subsection{Is the quality of the vowel predictable?}

The morphological and the phonological status of the linker vowel have not been discussed much in the literature on Russian compounds, so we need to start with a bit of background. According to Molinsky (1973), the linking vowel was borrowed in the 9th century from Greek along with 
the entire thematic compound structure through calquing. A similar element is found in Greek loans in English ("psych-o-logy"), and it occurs in Modern Greek compounds such as /kukl-o-spito/ [kuklóspito] 'doll house' (Nespor \& Ralli 1996, 1994). In Modern Russian, the linker is not obligatory for all compounds - it is absent in truncating and coordinating compounds, after allbut subordinating compounds always have it.

In Greek, the linker can be (and has been) analyzed as epenthetic. The linker vowel is always [o], and it alternates with zero predictably. It surfaces when the following stem starts with a consonant, but not when the following stem starts with a vowel. Thus, both epenthetic and deletion analyses are possible, and have been proposed (see Ralli 2003 for an overview). In Russian, on the other hand, the quality of the linker is only mostly predictable. Some examples are shown in (57). With one systematic exception (57c), the generalization is that the vowel is back if the last consonant of the preceding morpheme is velarized (see 57a), and it is front if the consonant is palatalized (see 57b). ${ }^{23}$ The systematic exception involves back palatal fricatives [3] and [ $]$. Although in unstressed syllables, these consonants will surface with a back vowel, as expected, (see 57c), in stressed syllables, the vowel is front, or at least unrounded (see 57c'). The examples in (d) demonstrate that other back consonants surface with $[\mathrm{o}]$ in stressed syllables.

(57) Palatalization of preceding consonant can predict the backness of the linker

\begin{tabular}{|c|c|c|c|c|}
\hline \multirow[t]{3}{*}{ a. } & $\mathrm{t}^{\mathrm{j}} \mathrm{el}$ & 'body (gen. pl.)' & 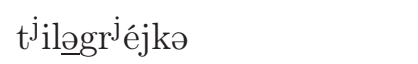 & 'wadded coat' \\
\hline & ikón & 'icon (gen. pl.)' & ikòn $\_$bórjits & 'iconoclast' \\
\hline & músər & 'garbage' (nom. sg.)' & mùsərə̣vós & 'garbage truck' \\
\hline \multirow[t]{3}{*}{ b. } & $\mathrm{pit}^{\mathrm{j}}$ & 'dust (nom. sg.)' & pil $1^{\mathrm{j}}$ isós & 'vacuum cleaner' \\
\hline & «gón ${ }^{\mathrm{j}}$ & 'fire (nom. sg.)' & əgn $\underline{j}_{\underline{i s t o ́ j k ə s t}} \mathrm{j}$ & 'fire resistance' \\
\hline & bur $^{\mathrm{j}}$ & 'storm (gen. pl.)' & bur $^{\mathrm{j}} \underline{\mathrm{iv}}^{\mathrm{j}}$ éstnik & 'stormy petrel' \\
\hline . & $\operatorname{lo} \int$ & 'lie (nom. sg.)' & 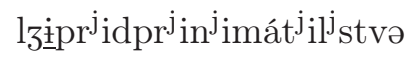 & 'fraudulent industry' \\
\hline$c^{\prime}$. & & & 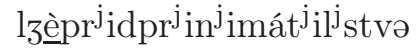 & \\
\hline d. & $\mathrm{l}^{\mathrm{j}} \mathrm{On}$ & 'linen (nom. sg.)' & $\mathrm{l}^{\mathrm{j}}$ nòz $\Lambda$ vót & 'linen factory' \\
\hline & don & 'bottom (gen. pl.)' & dnòuglubjítel ${ }^{\mathrm{j}}$ & 'dredger' \\
\hline
\end{tabular}

The pattern in (c-c') is not as surprising as it might initially appear. Historically, [3] is derived from $/ \mathrm{g} /$, and there are still morphophonological $[\mathrm{g}] \sim[3]$ alternations. Consider the verbal forms of 'lie,' for example: [lg-ú] 'I lie' vs. [lz-óf] 'you lie.' Space considerations preclude a complete analysis of the linker choice in compounds, but a phonological analysis seems necessary, since the vowel-consonant pairings are so predictable.

Despite this general regularity, there are a handful of cases where the same root appears with a back linker in some compounds and a front linker in others (see 58a). Even in these forms, the root-final consonant and the linker vowel agree in backness, but the backness of the the consonant-

\footnotetext{
${ }^{23}$ In some cases, the vowel is $<\mathrm{e}>$ in the orthography, but it is pronounced as the back vowel [i] , e.g., after [ts] or $\left[\int\right]$.
} 
vowel pair is unpredictable for any given compound. ${ }^{24}$ The choice of linker in these cases is not determined by the right-hand stem, however - compare (58a) and (58b). It should be noted that the

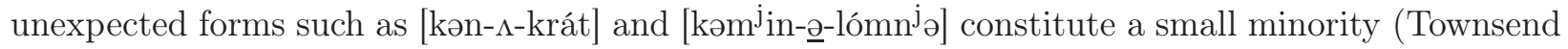
1975:202). It is possible that they are lexically listed exceptions, but even for these exceptional stems, the only necessary piece of information that needs to be stored is whether the stem-final consonant retains its palatalization or not.

(58) Some exceptions: idiosyncracy in the choice of linker

\begin{tabular}{|c|c|c|c|}
\hline \multirow{3}{*}{$\begin{array}{l}\text { a. } \\
\text { kon }^{j}\end{array}$} & \multicolumn{3}{|l|}{ Exceptions } \\
\hline & 'horse' & kən- $\Lambda$-krát & 'horse thief' \\
\hline & & kən $n^{\mathrm{j}}-\underline{\mathrm{i}}$-vótstvə & 'horse breeding' \\
\hline \multirow[t]{2}{*}{$\operatorname{kám}^{\mathrm{j}} \mathrm{in}^{\mathrm{j}}$} & 'stone' & kəmin-ə̃-lómn ${ }^{\mathrm{j}}{ }_{\partial}$ & 'quarry' \\
\hline & & kəmn j-í-pát & 'rockfall' \\
\hline b. & Regular forms & & \\
\hline $\mathrm{sol}^{\mathrm{j}}$ & 'salt' & səl ${ }^{\mathrm{j}}-\underline{\mathrm{i}}-\mathrm{krát}$ & 'salt thief' \\
\hline sıbák & 'dog (gen. pl.)' & səbək- $\underline{\Lambda}$-vótstvə & 'dog breeding' \\
\hline $\mathrm{sol}^{\mathrm{j}}$ & 'salt' & səl $l^{\mathrm{j}}-\underline{i}-l o ́ m n^{\mathrm{j}}$ & 'salt mine' \\
\hline $\mathrm{l}^{\mathrm{j}} \mathrm{ot}$ & 'ice’ & $\mathrm{j}^{\mathrm{j}} \mathrm{id}-\underline{\Lambda}$-pát & 'icefall' \\
\hline
\end{tabular}

Thus, to summarize, there is a phonological generalization as to the choice of linker: if the linker is stressed, then it is [e] if the preceding consonant is palatalized or alveo-palatal $\left(\int, 3\right)$ but $[\mathrm{o}]$ otherwise. If the linker is unstressed, it is never rounded or low, and it matches the palatalization of the preceding consonant. These facts could therefore be consistent with an epenthetic analysis. The evidence I discuss in the next section, on the other hand, is not consistent with epenthesis.

\subsection{Evidence against epenthesis}

This section discusses two kinds of evidence for the morphological status of the linking vowel. First, I show that vowel epenthesis is difficult to motivate phonotactically (see Section 4.3.1). Second, I show that the patterns of idiosyncratic vowel deletion in compounds also point to the morphological status of the linker.

\subsubsection{Russian linker vowels in a variety of contexts}

The first argument as to the morphological status of Russian linkers comes from the syllabic contexts in which they surface. Unlike the Greek linker, the Russian linker cannot be analyzed as epenthetic. From a long line of research on epenthesis, we know that vowels are often motivated by avoidance of unpronounceable consonant clusters or codas, but epenthetic vowels normally do not appear in

\footnotetext{
${ }^{24}$ Note also that in the case of compounds involving the root $\left[\mathrm{kam}^{\mathrm{j}} \mathrm{in}^{\mathrm{j}}\right.$ ], the second vowel alternates with zero only some of the time. I will return to this in Section 4.3.2.
} 
hiatus (Prince \& Smolensky 2004:6). The linker in Russian subordinating compounds is obligatory regardless of phonological context: it appears whether followed by a vowel or a consonant, as shown in (59). It is not always the case that the consonants on either side of the linker vowel can form a pronounceable medial cluster if the vowel were absent (recall 56), but there are plenty of contexts where they can (see 59b).

(59) Russian linking vowels in various phonological contexts

a. before vowel-initial stems:

$\begin{array}{lll}\text { /gaz-o-ekspluat-ats-ij-a/ } & \text { gà.zə.ek.splu.ı.tá.tsi.jə } & \text { 'gas utility' } \\ \text { /vod-o-ob-mjen/ } & \text { və.də.ムb.mén } & \text { 'water exchange' } \\ \text { /bjeton-o-u-klad-k-a/ } & \text { bji.tó.nə.u.klát.kə }^{j} & \text { 'concrete pouring' }\end{array}$

b. before consonant-initial stems:

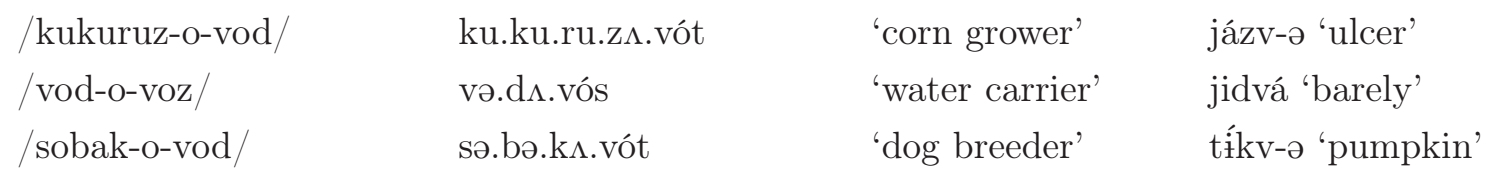

This cannot be epenthesis. The cluster that would arise if the vowel were not present is often perfectly acceptable, so the vowel cannot be inserted to avoid a coda or a marked onset cluster. Moreover, the vowel surfaces even before another vowel, which creates hiatus (a marked configuration cross-linguistically). The only potential benefit of inserting in this context is to prevent resyllabification across morpheme boundaries, to avoid something like *[və.d- $\Lambda$ b.m ${ }^{j}$ én]. Russian has no problem with this kind of resyllabification in other contexts, however: witness [k- $\Lambda$ b.- $m^{j}$ é.n-u] 'towards exchange'. The linker vowel must be a morpheme; there is simply no reason in Russian to epenthesize a vowel in this context. ${ }^{25}$

\subsubsection{Linkers and yer stems}

Additional evidence for the morphological status of the linking vowel comes from the behavior of Russian ghost vowels, or yers (jers). Yers are vowels that idiosyncratically alternate with zero in contexts where full, non-yer vowels do not alternate, as illustrated by the near-minimal pair in (60). ${ }^{26}$ Research has established that yers in Russian cannot be analyzed as epenthetic, since their quality is partially unpredictable (Yearley 1995; inter alia). In stressed syllables, a yer can be either front or back.

\footnotetext{
${ }^{25}$ It should be noted that hiatus is sometimes taken to be evidence of a prosodic word boundary in Russian (Gribanova 2009; Zubritskaya 1995). Examples of hiatus inside morpheme boundaries are certainly numerous, however,

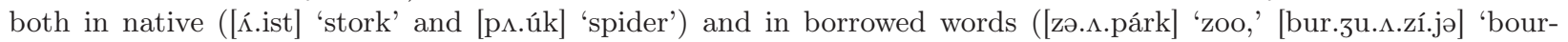
geousie') (see Padgett 2006 for more). Hiatus is resolved by vowel deletion at the root-suffix boundary (Halle \& Matushansky 2006:366), but it is not a general rule of Russian phonology, and it does not uniquely diagnose prosodic word boundaries. Avanesov mentions elision in hiatus at the prefix-root boundary as a feature of very informal colloquial speech (1968:106ff), though it is not a feature of my dialect.

${ }^{26} \mathrm{~A}$ number of examples in the article exhibit an alternation between [e] and [o]. This backing rule is somewhat morphologically idiosyncratic and probably no longer productive; but when it does apply, the context is a stressed syllable before a non-palatalized consonant (Lightner 1969).
} 


\section{Regular vowels: $\quad$ Yers: \\ $/ \mathrm{l}^{\mathrm{j}} \mathrm{en}^{\mathrm{j}} / \quad \mathrm{l}^{\mathrm{j}} \mathrm{en}^{\mathrm{j}} \quad$ 'laziness (nom. sg.)' $/ \mathrm{l}^{\mathrm{j}} \mathrm{En} / \quad \mathrm{l}^{\mathrm{j}} \mathrm{on} \quad$ 'linen (nom. sg.)'

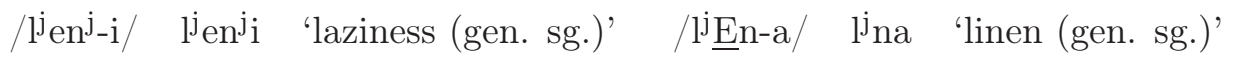

The patterns of yer realization are too complex to review here in detail (Lightner 1972; Melvold 1990; Yearley 1995; Scheer 2006; Steriopolo 2007; Gribanova 2008, 2009; Gouskova 2010), but it is generally true that a yer surfaces unless its deletion would yield an unsyllabifiable cluster, including a vowelless word. ${ }^{27}$ This generalization is exemplified in (61), where the deleting yers are underlined in the URs. I follow the tradition in Slavic phonology of writing yers with capital letters in underlying representations.

(61) Yer realization patterns
a. $/ \mathrm{sOn} /$
son
'dream (nom. sg.)'
/s $\underline{\text { On}}-\mathrm{a} /$
sna
'dream (gen. sg.)'
/sOn-it ${ }^{\mathrm{j}} \mathrm{s}^{\mathrm{j}} \mathrm{a} /$
snítsə
b. $/ 1^{\mathrm{j}} \operatorname{En} /$
$\mathrm{l}^{\mathrm{j}}$ on
'to appear in a dream'
$/ \mathrm{l}^{\mathrm{j}} \underline{\mathrm{En}}-\mathrm{u} /$
$\mathrm{j}^{\mathrm{j}}$ nú
$/ 1^{\mathrm{j}} \underline{\underline{E n}-{ }^{\mathrm{j}} \text { an-oj/ }}$
$\mathrm{j}^{\mathrm{j}} \mathrm{n}^{\mathrm{j}}$ inój
'linen (nom. sg.)'
c. /xlopOk/
xlópək (*xlópk)
/xlopㅁ-a/
xlópkə
'linen (dat sg)'
'linen (adj)'
d. $/ \mathrm{l}^{\mathrm{j}} \mathrm{Est}^{\mathrm{j}} /$
$\mathrm{l}^{\mathrm{j}}$ est $^{\mathrm{j}}$
$/ \mathrm{j}^{\mathrm{j}} \underline{\mathrm{Est}}^{\mathrm{it}} \mathrm{i}^{\mathrm{j}} /$
$\mathrm{l}^{\mathrm{j}} \mathrm{st}^{\mathrm{j}} \mathrm{i}^{\mathrm{j}}$
'cotton (nom. sg.)'
$/ \operatorname{podO}-\mathrm{l}^{\mathrm{j}} \underline{\mathrm{Est}}^{\mathrm{j}}-\mathrm{it}^{\mathrm{j}}-\mathrm{s}^{\mathrm{j}} \mathrm{a} /$
$\operatorname{pəd} \Lambda \mathrm{l}^{\mathrm{j}} \mathrm{st}^{\mathrm{j}} \mathrm{its} ə$
'cotton (gen. sg.)'
$/ \mathrm{l}^{\mathrm{j}} \mathrm{Est}^{\mathrm{j}}-\mathrm{Ets} /$
$\mathrm{j}^{\mathrm{j}} \mathrm{st}^{\mathrm{j}}$ éts
'flattery (nom. sg.)'
$/ \mathrm{l}^{\mathrm{j}}$ Est-n-ij /
ljés(t)nij (* $\left.\mathrm{l}^{\mathrm{j}} \mathrm{s}(\mathrm{t}) n i j\right)$
'to flatter'
'to smarm up'
'flatterer (nom. sg.)'
'flattering (adj)'

With this background on yers in non-compound words, we can appreciate the behavior of yercontaining stems in compounds. When a yer-containing stem is compounded, the yer almost always deletes: 28

\footnotetext{
${ }^{27}$ There are numerous complications and exceptions to the simple generalization stated above, both systematic and arbitrary, so the curious reader is referred to the various works cited.

${ }^{28} \mathrm{~A}$ curious complication concerns yers in prepositions when followed by compounds like $\left[\left[^{\mathrm{j}}\right.\right.$ noz $\Lambda$ vót]: speakers' intuitions differ as to whether the preferred form is [s $l^{j}$ noz $\Lambda$ vódom] or [so $l^{j}$ noz $\Lambda$ vódom]. According to the speakers I have consulted, both variants sound quite awkward - the preferred variant appears to be a null output (similar to the famous paradigm gaps in the genitive plural of CC-final stems). I have little to say about this at present, though it is an interesting problem for future research.
} 


\begin{tabular}{|c|c|c|c|}
\hline /s $\underline{\mathrm{On}}-\mathrm{O}-\mathrm{v}^{\mathrm{j}} \mathrm{id}-\mathrm{en}-\mathrm{ij}-\mathrm{o} /$ & $\operatorname{sn} \Lambda v^{j} i^{j} e^{j} n^{j} i j ə$ & 'dream, vision' & cf. son 'dream' \\
\hline /xlopㅁk-o-vod/ & xləpk $\Lambda$ vót & 'cotton grower' & cf. xlopok 'cotton' \\
\hline /lEn-o-za-vod/ & $\mathrm{l}^{\mathrm{j}}$ nəzı vót & 'linen factory' & cf. $\mathrm{l}^{\mathrm{j}}$ on 'linen' \\
\hline /므-e-na-uk-a/ & lżin $u ́ k ə$ & 'pseudoscience' & cf. ló 'lie' \\
\hline /otEts-e-u-b jij-stv-o/ & ətsiubjíjistvə & 'patricide' & cf. $\Lambda \mathrm{t}^{\mathrm{j} e ́ t s}$ 'father' \\
\hline
\end{tabular}

In order to account for yer deletion in compounds, the linking vowel must be posited underlyingly under practically anyone's account of yers. The most popular view of yers is that they are underlyingly representationally defective: they are either moraless vowels (Yearley 1995) or, almost equivalently, feature bundles that do not have associated timing units or root nodes (Kenstowicz \& Rubach 1987; Rubach 1986; Melvold 1990; Szpyra 1992; Zoll 1996). The reason yers are deleted so regularly is that their realization incurs a cost: a timing unit/mora must be added. Under Yearley's Optimality-Theoretic analysis, realizing a yer costs a faithfulness violation (DEP- $\mu$ in Correspondence-Theoretic terms), so yers will be deleted unless such deletion would violate certain syllable structure constraints. If the linking vowel is not lexical but is inserted by the phonology, DEP- $\mu$ is also violated, since all parts of an epenthetic vowel violate faithfulness - features, root node, and mora. Epenthesis does not make sense in this account: why insert a full vowel when half a vowel is already present elsewhere in the input? As shown below, this analysis predicts that the yer will surface, since realizing it violates a subset of faithfulness constraints compared to epenthesizing a vowel.

(63) Realization of a yer vs. an epenthetic linker (non-workable analysis)

\begin{tabular}{|c|c|c|c|}
\hline$/ \mathrm{l}^{\mathrm{j} E n-\operatorname{vod} /}$ & PhONOTACTICS & $\overline{\mathrm{DEP}}-\mu$ & DEP-V \\
\hline 鼍 ${ }^{\mathrm{j}} \mathrm{n} \Lambda$ vót & & * & * \\
\hline $\mathrm{l}^{\mathrm{j}}$ invót & & $*$ & $\overline{\mathrm{L}}$ \\
\hline $\mathrm{l}^{\mathrm{j}}$ nvót & ${ }^{*} \mathrm{~W}$ & $\mathrm{~L}$ & $\mathrm{~L}$ \\
\hline
\end{tabular}

The vowel must be lexical in rule-based accounts, as well. Most of the rule-based analyses, starting with Lightner (1972) and Pesetsky (1979), assume that yers delete unless followed by another yer in the UR. In order for the yer to delete in a compound, it needs to be followed by a non-yer vowel that allows for the resulting consonant cluster to be syllabified. Thus, yer stems supply an additional argument, even if it is theory-internal, that the linking vowel must be lexical. ${ }^{29}$

\footnotetext{
${ }^{29}$ There are a handful of exceptions to the generalization that yers delete in compound formation. The most variable stem in this respect is $/ \mathrm{l}^{\mathrm{j}} \mathrm{Ed}-/$ 'ice,' which appears to lose its yer vowel in some compounds but not in all. Indeed, the most frequently used compounds with 'ice' realize the yer:

(i) Non-deleting yers in compounds

$/ \mathrm{l}^{\mathrm{j}} \mathrm{Ed}-\mathrm{o}-\mathrm{kol} / \quad \mathrm{l}^{\mathrm{j}} \mathrm{id} \Lambda \mathrm{kól} \quad$ 'ice breaker ship' * * $\mathrm{l}^{\mathrm{j}} \mathrm{d} \Lambda \mathrm{kó}$

$/ \mathrm{l}^{\mathrm{j}} \mathrm{Ed}-\mathrm{o}-\mathrm{kat} / \quad \mathrm{j}^{\mathrm{j} i d} \Lambda$ kát 'a type of sleigh' * * j d $\Lambda$ kát

$/ \mathrm{l}^{\mathrm{j}} \mathrm{Ed}$-o-drom/ $\quad \mathrm{l}^{\mathrm{j}} \mathrm{id} \Lambda$ dróm 'ice rink' $\quad * \mathrm{l}^{\mathrm{j}} \mathrm{d} \Lambda$ dróm

In these compounds, yer deletion is completely unacceptable, as indicated above. For other compounds, however, both yer-less and yer-ful variants are attested:
} 
To summarize, then, two facts of Russian phonology point to the lexical status of the linking vowel. First, it appears in a variety of phonological contexts, so it is unlikely to be epenthesized for reasons of syllable structure. Second, the linking vowel conditions yer deletion, which requires that the vowel be lexical both in Optimality-Theoretic and rule-based accounts. Thus it cannot be the case that the linker vowel resists stress because it is epenthetic; it must be present in the UR. There is, however, an alternative explanation for its resistance to stress, namely, that it is unaccented (see Section 2.2.3).

\section{Conclusion}

In Russian, phonological diagnostics of multiple prosodic words yield conflicting results when applied to compounds. On the one hand, compounds are the only context where secondary stress is found, which suggests that they may be made up of multiple prosodic words. On the other hand, juncturesensitive rules of Russian do not treat the boundary between stems as a prosodic word boundary. I proposed an analysis of voicing and vowel reduction, which covers the behavior of a range of syntactic entities including clitics and compounds. I also presented some arguments from the phonology of Russian that the linker vowel, found between the stems of compounds, is morphological as opposed to inserted by the phonology.

My analysis made no use of recursive prosodic word structure or the clitic group level. Recursive prosodic word structure is inappropriate for Russian compounds because there is no evidence of internal prosodic word boundaries in compounds. Analyzing compounds as clitic groups is wrong for the same reason. Thus, Russian contributes an interesting case to the typology of the prosodic structure of compounds. In languages such as English and Icelandic, compounds are fruitfully analyzed as consisting of multiple prosodic words. Languages such as Russian and Greek, on the other hand, present a more complicated picture, requiring an analysis that can derive some properties associated with prosodic words without positing multiple prosodic words. The appearance of phonological word recursion is sometimes just that - an appearance.

(ii) Free variation in yer realization for $/ \mathrm{l}^{\mathrm{j}} \mathrm{Ed}-/$

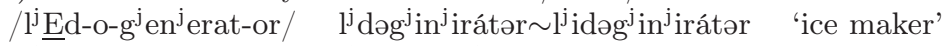

$/ \mathrm{l}^{\mathrm{j}} \underline{\mathrm{E}} \mathrm{d}-\mathrm{o}-\mathrm{bur} / \quad \mathrm{l}^{\mathrm{j}} \mathrm{d} \Lambda$ búr $\sim \mathrm{l}^{\mathrm{j}} \mathrm{id} \Lambda$ búr $\quad$ 'ice drill'

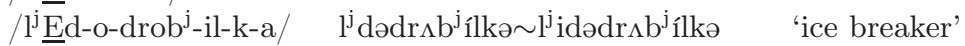

It appears, however, that this root is exceptional in more than one way: it is likely to keep its yer where other yer stems lose theirs. Consider the contrast between $\left[\mathrm{l}^{\mathrm{j}} \mathrm{id} \mathrm{j}^{\mathrm{j} i n o ́ j]}\right.$ 'icy' and $\left[\mathrm{l}^{\mathrm{j}} \mathrm{n}^{\mathrm{j}} \mathrm{inój}\right]$ 'linen-adj' below, as well as the instances where the yer is preserved even though it is followed by a non-yer vowel-initial suffix.

(iii) Exceptional behavior of $/ \mathrm{l}^{\mathrm{j}} \mathrm{Ed}-/$

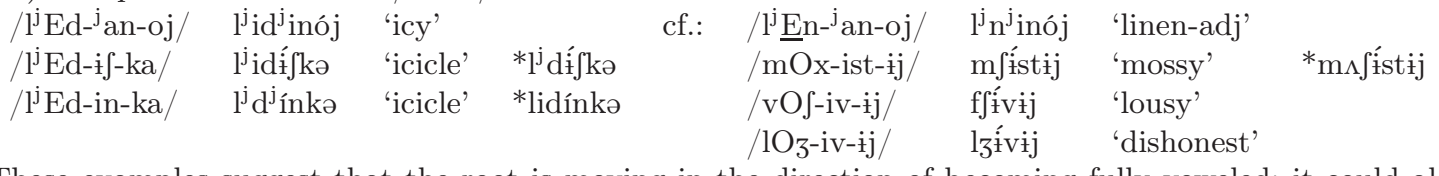

These examples suggest that the root is moving in the direction of becoming fully voweled; it could also be that the extremely marked sonority contour of the cluster idiosyncratically blocks yer deletion. The same cannot be said for the stem $/ \mathrm{kam}^{\mathrm{j}} \mathrm{En}^{\mathrm{j}}$ / 'stone' (recall 58), so the problem is far from solved. 


\section{References}

Alderete, John. 1999a. Head dependence in stress-epenthesis interaction. In Ben Hermans \& Marc van Oostendorp (eds.), The Derivational residue in optimality theory, 29-50. Amsterdam: John Benjamins.

Alderete, John. 1999b. Morphologically-governed accent in optimality theory. Amherst, MA: University of Massachusetts, Amherst dissertation.

Al'muxamedova, Z. M. \& R. E. Kul'sharipova. 1980. Reduktsija glasnyx i prosodija slova v okajushchix russkix govorax /Vowel reduction and word prosody in okan'e dialects of Russian.]. Kazan': Izdatel'stvo Kazanskogo Universiteta.

Avanesov, R. I. 1968. Russkoe literaturnoe proiznoshenie [Literary pronunciation of Russian]. Moscow: Izdatelstvo Prosvescenie 6th edn.

Barnes, Jonathan. 2004. Vowel reduction in Russian: The categorical and the gradient, Boston. Handout from LSA 78.

Becker, Michael. 2008. Phonological trends in the lexicon: The role of constraints. Amherst, MA: University of Massachusetts dissertation.

Beckman, Jill. 1997. Positional faithfulness, positional neutralization, and Shona vowel harmony. Phonology 14(1). 1-46.

Beckman, Jill N. 1998. Positional faithfulness: University of Massachusetts, Amherst dissertation. New York: Routledge.

Benua, Laura. 1997. Transderivational identity: Phonological relations between words: University of Massachusetts, Amherst dissertation. Available on the Rutgers Optimality Archive, ROA-259, http://roa.rutgers.edu.

Bethin, Christina. 2006. Stress and tone in East Slavic dialects. Phonology 23(3). 125-156.

Blumenfeld, Lev. 2003. Russian palatalization in Stratal OT: morphology and [back]. In Wayles Browne, Ji-yung Kim, Barbara H. Partee \& Robert Rothstein (eds.), Proceedings of FASL 11. University of Massachusetts, Amherst, 141-158. Ann Arbor: Michigan Slavic Publications.

Boersma, Paul \& David Weenink. 2009. Praat: Doing phonetics by computer, version 5.1.

Booij, Geert. 1995. The phonology of Dutch. Oxford: Clarendon Press.

Broselow, Ellen. 2008. Stress-epenthesis interactions. In Bert Vaux \& Andrew Nevins (eds.), Rules, constraints, and phonological phenomena, 121-149. Oxford: Oxford University Press.

Crosswhite, Katherine. 1999. Vowel reduction in optimality theory. Los Angeles: UCLA dissertation.

Crosswhite, Katherine, John Alderete, Tim Beasley \& Vita Markman. 2003. Morphological effects on default stress placement in novel Russian words. In Gina Garding \& Mimu Tsujimura (eds.), Proceedings of WCCFL 22, 151-164. Somerville, MA: Cascadilla Press.

Fitzgerald, Colleen. 2001. The morpheme-to-stress principle in Tohono O'odham. Linguistics 39(5). 941-972. 
Flack, Kathryn. 2007. Templatic morphology and indexed markedness constraints. Linguistic Inquiry 38(4). 749-758.

Gouskova, Maria. 2010. Unexceptional segments. Ms. NYU.

Gouskova, Maria \& Kevin Roon. 2008. Interface constraints and frequency in Russian compound stress. In Jodi Reich, Maria Babyonyshev \& Darya Kavitskaya (eds.), Proceedings of FASL 17, 49-63. Ann Arbor, MI: Michigan Slavic Publications.

Gouskova, Maria \& Kevin Roon. 2010. Secondary stress in Russian: a grammaticality judgment study. Ms. NYU.

Gribanova, Vera. 2008. Russian prefixes, prepositions and palatalization in stratal OT. In Charles B. Change \& Hannah J. Haynie (eds.), Proceedings of WCCFL 26, 217-225. Somerville, MA: Cascadilla Press.

Gribanova, Vera. 2009. Phonological evidence for a distinction between Russian prepositions and prefixes. In Gerhild Zybatow, Uwe Junghanns, Denisa Lenertová \& Petr Biskup (eds.), Studies in formal Slavic phonology, morphology, syntax, semantics and information structure: Proceedings of the 7th European conference on formal description of Slavic languages, 383-396. Frankfurt am Main: Peter Lang Verlag.

Hall, T. Alan \& Ursula Kleinhenz (eds.). 1999. Studies on the phonological word. Amsterdam: John Benjamins.

Halle, Morris. 1973. The accentuation of Russian words. Language 49(2). 312-348.

Halle, Morris. 1996. On stress and accent in Indo-European. Language 73(2). 275-313.

Halle, Morris \& Michael Kenstowicz. 1991. The free element condition and cyclic versus noncyclic stress. Linguistic Inquiry 22(3). 457-501.

Halle, Morris \& Ora Matushansky. 2006. The morphophonology of Russian adjectival inflection. Linguistic Inquiry 37(3). 351-404.

Halle, Morris \& K. P. Mohanan. 1985. Segmental phonology of Modern English. Linguistic Inquiry 16(1). 57-116.

Halle, Morris \& Jean-Roger Vergnaud. 1987a. An essay on Stress. Cambridge, MA: MIT Press.

Halle, Morris \& Jean-Roger Vergnaud. 1987b. Stress and the cycle. Linguistic Inquiry 18(1). 45-84.

Harley, Heidi. 2008. Compounding in Distributed Morphology. In Rochelle Lieber \& Pavol Stekauer (eds.), Oxford handbook of compounding, 129-144. Oxford: Oxford University Press.

Hayes, Bruce. 1984. The phonetics and phonology of Russian voicing assimilation. In Mark Aronoff \& Richard T. Oehrle (eds.), Language sound structure, 318-328. Cambridge, MA: MIT Press.

Hayes, Bruce. 1989. The prosodic hierarchy in meter. In Paul Kiparsky \& G. Youmans (eds.), Rhythm and meter, 201-260. Orlando: Academic Press.

Idsardi, William. 1992. The computation of prosody. Cambridge, MA: MIT

Inkelas, Sharon. 1996. Dominant affixes and the phonology-morphology interface. In Ursula Kleinhenz (ed.), Studia grammatica, vol. 41 Interfaces in phonology, 128-154. Berlin: Akademie Verlag. 
Ito, Junko \& Armin Mester. 1999. Realignment. In René Kager, Harry van der Hulst \& Wim Zonneveld (eds.), The prosody-morphology interface, 188-217. Cambridge: Cambridge University Press.

Ito, Junko \& Armin Mester. 2003. On the sources of opacity in OT: Coda processes in German. In Caroline Féry \& Ruben van de Vijver (eds.), The syllable in optimality theory, 271-304. Cambridge: Cambridge University Press.

Ito, Junko \& Armin Mester. 2006. Prosodic adjunction in Japanese compounds. In Yoichi Miyamoto \& Masao Ochi (eds.), The proceedings of Formal Approaches to Japanese Linguistics 4, 97-112. Cambridge, MA: MITWPL 55.

Ito, Junko \& Armin Mester. 2009. The onset of the prosodic word. In Steve Parker (ed.), Phonological argumentation: Essays on evidence and motivation, 227-260. London: Equinox.

Kabak, Baris \& Anthi Revithiadou. 2008. An interface approach to prosodic word recursion. In Janet Grijzenhout \& Baris Kabak (eds.), Phonological domains: Universals and deviations, 105-133. Berlin: Mouton de Gruyter.

Kabak, Baris \& Irene Vogel. 2001. The phonological word and stress assignment in Turkish. Phonology 18(4). 315-360.

Kager, René. 1994. Ternary rhythm in alignment theory. Ms. Available on the Rutgers Optimality Archive as ROA-35.

Kager, René. 2001. Rhythmic directionality by positional licensing, University of Potsdam. Handout from HILP 5. Available on the Rutgers Optimality Archive, ROA 514, http://roa.rutgers.edu.

Kasatkina, Rosalia. F. \& E. V. Shchigel'. 1996. Osobennosti prosodii slova v juzhnorusskix govorax [word prosody in south Russian dialects]. In T. M. Nikolaeva (ed.), Prosodicheskij stroj russkoj rechi [the prosodic structure of Russian speech], 236-255. Moscow: Russkaja Akademija Nauk.

Kawahara, Shigeto. 2007. On the proper treatment of non-crisp edges. In Mutsuko Hudson Endo, Peter Sells \& Sun-Ah Jun (eds.), Japanese/Korean linguistics, vol. 13, 55-67. Stanford, CA: CSLI Publications.

Kenstowicz, Michael \& Jerzy Rubach. 1987. The phonology of syllabic nuclei in Slovak. Language 63(3). 463-497.

Kiparsky, Paul. 1985. Some consequences of Lexical Phonology. Phonology 2. 85-138.

Kiparsky, Paul. to appear. Paradigm effects and opacity. Stanford, CA: CSLI.

Kuznetsova, E. V. 2006. Acoustic parameters of secondary stress in Russian. In Proceedings of the XVIII meeting of the Russian Acoustical Society, 547-550. http://www.akin.ru/Docs/Rao/Ses18/R18.PDF. (accessed on Jan. 4, 2007).: GEOS.

de Lacy, Paul. 2002. The formal expression of markedness. Amherst, MA: University of Massachusetts, Amherst dissertation.

Liberman, Mark \& Alan Prince. 1977. On stress and linguistic rhythm. Linguistic Inquiry 8(2). 249-336.

Lightner, Theodore. 1969. On the e $\sim$ o alternation in Modern Russian. Linguistics 54(1). 44-69. 
Lightner, Theodore. 1972. Problems in the theory of phonology. Edmonton: Linguistic Research, Inc.

Lombardi, Linda. 1999. Positional faithfulness and voicing assimilation in optimality theory. Natural Language and Linguistic Theory 17(2). 267-302.

Lombardi, Linda. 2001. Why place and voice are different: Constraint-specific alternations in optimality theory. In Linda Lombardi (ed.), Segmental phonology in optimality theory: Constraints and representations, 13-45. Cambridge: Cambridge University Press. Available (1995) on Rutgers Optimality Archive.

Marantz, Alec. 1997. No escape from syntax: don't try morphological analysis in the privacy of your own lexicon. In Alexis Dimitriadis, Laura Siegel, Clarissa Surek-Clark \& Alexander Williams (eds.), University of Pennsylvania working papers in linguistics: Proceedings of the 21st Annual Penn Colloquium, vol. 4.2, 201-225.

Marantz, Alec. 2008. Phases and words. Ms. NYU.

Mascaró, Joan. 1976. Phonology and the phonological cycle. Cambridge, MA: MIT dissertation.

McCarthy, John J. 2003. OT constraints are categorical. Phonology 20(1). 75-138.

McCarthy, John J. 2007. Hidden generalizations: Phonological opacity in optimality theory. London: Equinox.

McCarthy, John J. \& Alan Prince. 1986. Prosodic morphology. Technical Report \#32, Rutgers University Center for Cognitive Science, version of 1996.

McCarthy, John J. \& Alan Prince. 1993a. Generalized alignment. In Geert Booij \& Jaap van Marle (eds.), Yearbook of morphology, 79-153. Dordrecht: Kluwer.

McCarthy, John J. \& Alan Prince. 1993b. Prosodic morphology I: Constraint interaction and satisfaction. New Brunswick: Rutgers University Center for Cognitive Science. Available on the Rutgers Optimality Archive, ROA 482, http://roa.rutgers.edu.

Melvold, Janis. 1990. Structure and stress in the phonology of Russian. Cambridge, MA: MIT dissertation.

Molinsky, Steven J. 1973. Patterns of ellipsis in Russian compound noun formation. The Hague: Mouton.

Nespor, Marina \& Angela Ralli. 1994. Stress domains in Greek compounds: a case of morphologyphonology interaction. In Irene Philippaki-Warburton, Katerina Nicoladis \& Maria Sifianou (eds.), Themes in Greek linguistics, 201-208. Amsterdam: John Benjamins.

Nespor, Marina \& Angela Ralli. 1996. Morphology-phonology interface: phonological domains in Greek compounds. The Linguistic Review 13. 357-382.

Nespor, Marina \& Irene Vogel. 1986. Prosodic phonology. Dordrecht: Foris.

Nespor, Marina \& Irene Vogel. 1989. On clashes and lapses. Phonology 6. 69-116.

Orešnik, Janez. 1971. On the phonological boundary between constituents of modern Icelandic compound words. Linguistica 11. 51-59. 
Padgett, Jaye. 2001. Contrast dispersion and Russian palatalization. In Elizabeth Hume \& Keith Johnson (eds.), The role of speech perception in phonology, 187-218. San Diego: Academic Press.

Padgett, Jaye. 2003. Contrast and postvelar fronting in Russian. Natural Language and Linguistic Theory 21. 39-87.

Padgett, Jaye. 2006. Glides, vowels, and features. Ms. UC Santa Cruz.

Padgett, Jaye. to appear. Russian voicing assimilation, final devoicing, and the problem of [v] (or, The mouse that squeaked). NLLT .

Padgett, Jaye \& Marija Tabain. 2005. Adaptive dispersion theory and phonological vowel reduction in Russian. Phonetica 62(1). 14-54.

Pater, Joe. 2000. Nonuniformity in English secondary stress: The role of ranked and lexically specific constraints. Phonology 17. 237-274.

Pater, Joe. 2001. Austronesian nasal substitution revisited: What's wrong with *NC (and what's not). In Linda Lombardi (ed.), Segmental phonology in optimality theory: Constraints and representations, 159-182. Cambridge: Cambridge University Press. Available (1995) on Rutgers Optimality Archive.

Pater, Joe. 2006. The locus of exceptionality: Morpheme-specific phonology as constraint indexation. In Leah Bateman, Michael O'Keefe, Ehren Reilly \& Adam Werle (eds.), Papers in optimality theory III, 259-296. Amherst, MA: GLSA.

Peperkamp, Sharon. 1997. Prosodic words. The Hague: Holland Academic Graphics. University of Amsterdam dissertation.

Pesetsky, David. 1979. Russian morphology and lexical theory. Ms. MIT.

Petrova, Olga, Rosemary Plapp, Catherine O. Ringen \& Szilárd Szentgyörgyi. 2006. Voice and aspiration: Evidence from Russian, Hungarian, German, Swedish, and Turkish. The Linguistic Review 23(1). 1-35.

Prince, Alan. 1983. Relating to the grid. Linguistic Inquiry 14. 19-100.

Prince, Alan. 2000. Comparative tableaux. Ms. Available on the Rutgers Optimality Archive as ROA-376.

Prince, Alan \& Paul Smolensky. 2004. Optimality theory: Constraint interaction in generative grammar. Malden, Mass., and Oxford, UK: Blackwell. Distributed in 1993 as ROA-537.

Ralli, Angela. 2003. Morphology in Greek linguistics. Journal of Greek Linguistics 4. 77-129.

Revithiadou, Anthi. 1999. Headmost accent wins: Head dominance and ideal prosodic form in lexical accent systems. The Hague: Holland Academic Graphics. University of Leiden dissertation.

Roon, Kevin. 2006. Stress in Russian compound nouns: head dominance or anti-faithfulness? In James E. Lavine, Steven Franks, Mila Tasseva-Kurktchieva \& Hana Filip (eds.), Proceedings of FASL 14, 319-330. Michigan Slavic Publications.

Rubach, Jerzy. 1986. Abstract vowels in three-dimensional phonology: The yers. The Linguistic Review 5. 247-280. 
Rubach, Jerzy. 1995. Representations and the organization of rules in Slavic phonology. In John A. Goldsmith (ed.), The handbook of phonological theory, 848-866. Cambridge, Mass., and Oxford, UK: Blackwell.

Rubach, Jerzy. 2000a. Backness switch in Russian. Phonology 17(1). 39-64.

Rubach, Jerzy. 2000b. Glide and glottal stop insertion in Slavic languages: A DOT analysis. Linguistic Inquiry 31(2). 271-317.

Scheer, Tobias. 2006. How yers made Lightner, Gussman, Rubach, Spencer and others invent CVCV. In Piotr Banski, Beata Lukaszewicz \& Monika Opalinska (eds.), Studies in constraintbased phonology, 133-207. Warsaw: Wydawnictwa Uniwersytetu Warszawskiego.

Selkirk, Elisabeth. 1984. Phonology and Syntax: The Relation between Sound and Structure. Cambridge, Mass.: MIT Press.

Selkirk, Elisabeth. 1995. The prosodic structure of function words. In Jill Beckman, Laura Walsh Dickey \& Suzanne Urbanczyk (eds.), University of Massachusetts Occasional Papers: Papers in optimality theory, 439-470. Amherst, MA: GLSA Publications.

Selkirk, Elisabeth \& Tong Shen. 1990. Prosodic domains in Shanghai Chinese. In Sharon Inkelas \& Draga Zec (eds.), The phonology-syntax connection, 313-337. Chicago: University of Chicago Press.

Selkirk, Elisabeth \& Koichi Tateishi. 1988. Constraints on minor phrase formation in Japanese. In Papers from the 24th annual regional meeting of the Chicago Linguistic Society, 316-336. Chicago: Chicago Linguistic Society.

Smith, Jennifer. 2002. Phonological Augmentation in Prominent Positions. Amherst, Mass.: University of Massachusetts, Amherst dissertation.

Steriade, Donca. 1995. Positional neutralization. Ms.

Steriade, Donca. 1999. Phonetics in phonology: the case of laryngeal neutralization. In Matthew Gordon (ed.), Papers in phonology 3 (UCLA working papers in linguistics 2), 25-145. Los Angeles: Department of Linguistics, University of California.

Steriopolo, Olga. 2007. Jer vowels in Russian prepositions. In Formal approaches to Slavic linguistics. the Toronto meeting 2006, 365-385. Ann Arbor, MI: Michigan Slavic Publications.

Stroganova, T. G. 1973. Vokalizm [Vowel systems]. In Piotr. S. Kuznetsov (ed.), Russkaja dialektologija [Russian dialectology], 35-77. Moscow: Prosveshchenije.

Szpyra, Jolanta. 1992. Ghost segments in nonlinear phonology: Polish yers. Language 68(2). 277312.

Townsend, Charles. 1975. Russian word-formation. Columbus: Slavica Publishers corrected reprint (1980) edn.

Ukiah, Nick. 1998. Stress retraction in phrases of the type na den', za sorok, ne byl in Modern Russian. Russian Linguistics 22(3). 287-319. 
Vysotskij, S. S. 1973. O zvukovoj strukture slova v russkix govorax [On the sound structure of words in Russian dialects]. In Ju. S. Azarx, S. V. Bromlej \& L. N. Bulatova (eds.), Issledovanija po russkoj dialektologii [research on Russian dialectology], 17-41. Moscow: Nauka.

Wade, Terence. 1992. A comprehensive Russian grammar. Cambridge: Blackwell.

Yearley, Jennifer. 1995. Jer vowels in Russian. In Jill Beckman, Laura Walsh Dickey \& Suzanne Urbanczyk (eds.), Papers in optimality theory II (University of Massachusetts occasional papers in linguistics), 533-571. Amherst, Mass.: GLSA Publications.

Yoo, Seung-Nam. 1992. Subsidiary stress in Russian compound words: University of Illinois at Urbana-Champaign dissertation.

Zaliznjak, Andrej Anatoljevich. 1977. Grammatičeskij slovar' russkogo jazyka [A grammatical dictionary of the Russian language]. Moscow: Russkij Jazyk.

Zec, Draga \& Sharon Inkelas. 1990. Prosodically constrained syntax. In Sharon Inkelas \& Draga Zec (eds.), The phonology-syntax connection, 365-378. Chicago: University of Chicago Press.

Zoll, Cheryl. 1996. Parsing below the Segment in a Constraint-based Framework: University of California, Berkeley dissertation. Available on the Rutgers Optimality Archive as ROA-143.

Zubritskaya, Katya. 1995. The categorical and variable phonology of Russian. Philadelphia: University of Pennsylvania dissertation.

\section{Appendix I}

The goal of this section is to formalize the NoSTRADDLING constraint introduced in $\S 3.2$. This constraint is related to constraints such as CRIspEdGe (Ito \& Mester 1999) and UniqueAffiliation (Kawahara 2007), which penalize multiple prosodic associations, ${ }^{30}$ and Generalized Alignment (McCarthy \& Prince 1993b). Neither CrispEdge nor UniqueAffiliation are sensitive to edgesthey penalize multiple affiliations regardless of where the offending segment is. The chief difference between CrispEdge and UniqueAffiliation is that the latter can be relativized to specific features, which is needed for Russian as well, as I will show shortly. In order to penalize multiple affiliation through feature sharing, I follow Ito and Mester in separating edge straddling through feature sharing from morpho-phonological alignment proper, which is defined on segments. My definition of NoStraddling combines some features of UniqueAffiliation and Alignment and is a natural extension of these schemata.

Straddling occurs when a segment that is at the edge of a string dominated by a prosodic category $\mathrm{PCat}_{1}$ shares features with another segment that is outside the relevant prosodic subtree - more precisely, a segment that is dominated by some prosodic category PCat 2 that neither dominates nor is dominated by PCat ${ }_{1}$. Three variables are manipulated by the NoSTRADDLing schema: (i) the

\footnotetext{
${ }^{30}$ Ito and Mester actually discuss the possibility of relativizing CRISPEDGE to left and right edges but do not pursue it. There are some cases that appear to necessitate asymmetric constraints on double affiliation, including English ambisyllabicity: a consonant may be ambisyllabic at the right edge of a foot but not at the left.
} 
edge, (ii) some linguistic entity whose affiliation is in question, e.g., a feature, and (iii) the prosodic category. The edge of a terminal string of PCat is identified by the Edge function, which returns the first (leftmost) or the last (rightmost) element of the terminal string:

\section{Definition of Edge:}

Let $\mathrm{S}$ be a terminal string of PCat.

$$
\begin{aligned}
& \text { L-Edge }(\mathrm{S})=\mathrm{d}_{i} \mid \mathrm{d}_{i} \in \mathrm{S} \text { and } \neg \exists \mathrm{d}_{j} \in \mathrm{S} \text { and } \mathrm{d}_{j} \prec \mathrm{d}_{i} . \\
& \mathrm{R} \text {-Edge }(\mathrm{S})=\mathrm{d}_{i} \mid \mathrm{d}_{i} \in \mathrm{S} \text { and } \neg \exists \mathrm{d}_{j} \in \mathrm{S} \text { and } \mathrm{d}_{j} \succ \mathrm{d}_{i} .
\end{aligned}
$$

In the definition below, I follow the standard assumption that segments dominate features that they are associated with, and that segments are in turn dominated by features. Straddling occurs, then, when a feature is dominated by two segments, one of which is not a constituent of the relevant category Cat. The standard notion of constituency, "is a," is represented in the definition below with the "三" symbol (following Ito \& Mester 1999).

(65) NoStradduing( $\alpha$, Edge, Cat): "If A is an Edge of Cat and $\alpha \equiv \mathrm{A}$, then there is no B such that $\alpha \equiv \mathrm{B}$ and $\neg \mathrm{B} \equiv$ Cat."

The constraint we need for Russian is NoStradduing(voice, L, PWd). This constraint is violated when the first segment of a prosodic word is linked to a feature that is shared with a segment to the left of a prosodic word boundary, as in (66a). It is satisfied when there is no sharing, as in (66b). When features are shared across the right edge of a prosodic word but not across the left, as in $\{[\mathrm{sad}] 3 \mathrm{e}\}$, NoSTRAdDLING is satisfied, since neither of the segments in the span of [voice] is a left edge of a PWd (not shown).

(66) Sharing of [voice] across a prosodic word boundary

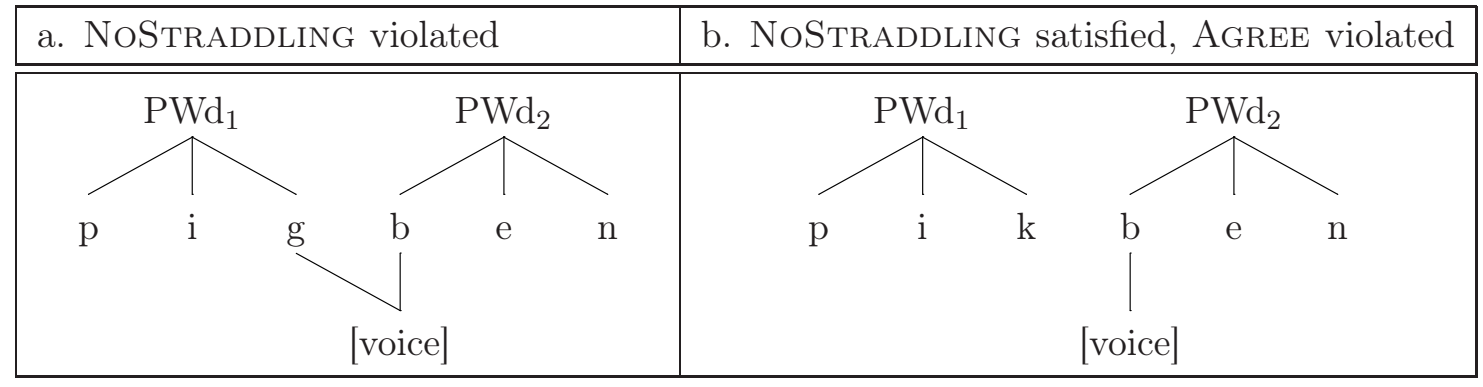

It must be assumed that Russian requires NOSTRADDLING constraints for different features. Unlike voicing, some features can actually be shared across the left edge. Consonants can share secondary articulation features (palatalization, velarization) with vowels that are separated from them by the left prosodic word boundary (Padgett 2001; Gribanova 2009; Zubritskaya 1995; Rubach 1995). The left edge of a prosodic word can be non-crisp for the purposes of CV agreement but not for voicing agreement, as shown in (67).

CV agreement straddles the left boundary 
/po-mog ivan-u/ p^mók ivánu '(someone) helped Ivan' cf. iván

/maz ivan-a/ mas iván-ə 'Ivan's ointment'

A simple CRISPEDGE cannot produce this pattern, since additional features shared across the boundary do not incur separate violations (see Kawahara 2007). In order to account for Russian voicing neutralization and CV agreement simultaneously, NoStradDLing(back, L, PWd) must be distinct from NoStraddling(voice, L, PWd).

\section{Appendix II}

Words analyzed in the acoustic study. Primary stress is shown for all words; secondary stress is shown for those that were realized with secondary stress. In some cases, the location of secondary stress varied, so all secondary stress locations are marked. Transcription is very broad, and vowel quality is as in the UR/orthography.

Type of stem 1
1. betòno-m $\mathrm{m}^{\mathrm{j}} \mathrm{e} a ́ l k a$
2. bòmbo-d $\mathrm{d}^{\mathrm{j}} \mathrm{er}$ átel $^{\mathrm{j}}$
3. èkskùrso-vód
4. golovo-kruzén ${ }^{\mathrm{j} i j e}$
5. golovo-lómka
6. golovo- $\mathrm{t}^{\mathrm{j} a ́ p}$
7. golovo-t $\mathrm{t}^{\mathrm{j}}$ ápstvo
8. ikòno-bór ${ }^{j}$ ets
9. jèst ${ }^{j}$ èstvo-v $^{\mathrm{j}} \mathrm{ed}^{\mathrm{j}} \mathrm{en}^{\mathrm{j}} \mathrm{ije}$
10. $\mathrm{k}^{\mathrm{j}}$ ino- $\mathrm{j}^{\mathrm{j}}$ énta

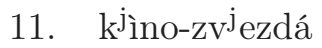
12. kùkurùzo-vód
13. jjèso-spláv
14. ma/îno-strojén ${ }^{\mathrm{j}}$ ije
15. ma/ìno-v $v^{j} e_{d e n}{ }^{j} i j e$

A

A 17 .

A 18 .

C 19

C 20 .

C 21 .

C 22 .

A 23 .

B 24 .

B 25 .

B 26 .

A 27 .

A 28 .

A 29 .

A 30 .
Type of stem 1

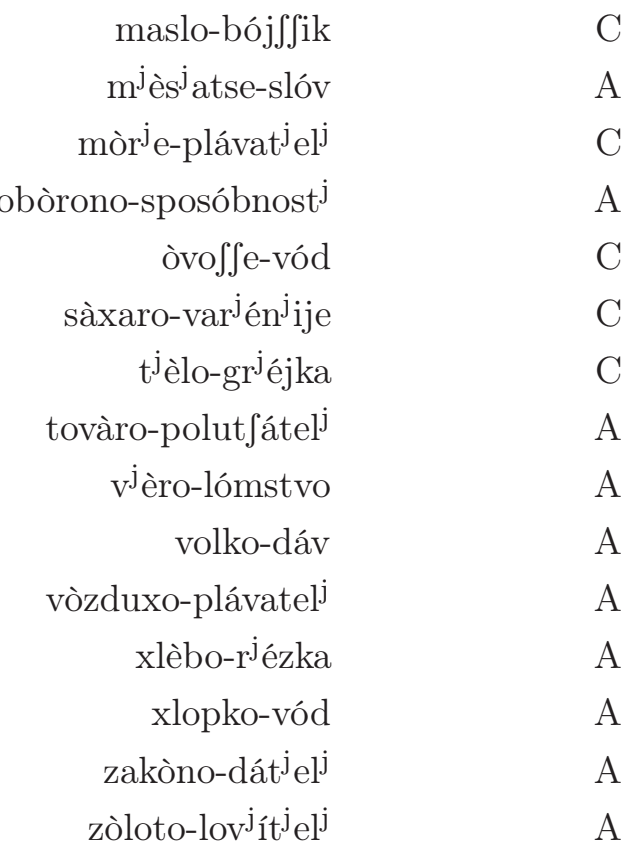

